\title{
Reclaiming the Past to Transcend the Present: Nostalgic Appeals in U.S. Presidential Elections
}

\author{
Bart Bonikowski $^{1}$ and Oscar Stuhler ${ }^{1}$ \\ ${ }^{1}$ New York University
}

\begin{abstract}
Nostalgic appeals to an idealized past are a commonly associated with radical-right discourse. They bolster candidates' critiques of the status quo and promises of a better future, all while mobilizing perceptions of collective status threat among supporters. In this paper, we ask whether nostalgia is a radical-right innovation or whether it has precedents in mainstream politics. We make use of recent advances in natural language processing - specifically transformer-based deep learning models - to identify nostalgic claims in U.S. presidential campaign speeches from 1952 to 2020 . We then examine what form nostalgia takes, when it has been most salient, what aspects of the nation it has been used to glorify, and how it relates to populist and nationalist appeals. Our findings suggest that nostalgic rhetoric usually takes the form of brief and multivocal statements with a consistent lexical signature. It is frequently used by challenger candidates from both parties to generate a heightened sense of crisis and to morally indict incumbent opponents, particularly during times of widespread cultural contention. In so doing, nostalgia helps substantiate candidates' populist claims and expressions of low national pride. Given that these patterns are found throughout our time series, this points to important continuities between the discourse of mainstream and radical-right actors in U.S. politics. Where their respective messaging diverges, however, is in the use of nostalgia to frame exclusionary nationalist and authoritarian appeals, a practice limited to the radical-right (in our data, Donald Trump). Our findings suggest that radicalright actors did not invent their rhetorical strategies de novo, but rather, have adopted frames already widespread in mainstream politics, adapting and creatively recombining them for their own ends.
\end{abstract}




\section{Introduction}

The main theme of Donald Trump's 2016 presidential campaign was encapsulated by the punchy slogan, "Make America Great Again." This phrase not only helped mobilize Trump voters but also became a locus of collective identity, with the acronym "MAGA" uniting disaffected right-wing supporters across the country and serving as a lasting marker of symbolic boundaries between the Trump camp and the rest of the American public. At its core, the slogan evoked a sense of a bygone golden age that ought to be reclaimed if the country is to thrive again (Smith, 2009). That is, it was an expression of national nostalgia.

The Trump campaign, however, was not unique in its nostalgic appeals. Scholars have increasingly recognized nostalgia to be a common feature of radical politics across Western democracies, in countries as different as the United Kingdom (Richards et al., 2020), Spain (Muro, 2005), Sweden (Elgenius and Rydgren, 2019), Hungary (Szabó and Kiss, 2021), and Turkey (Karakaya, 2020). Glorifying the past and disparaging the present enables a wide range of radical party leaders to indict the political establishment for having failed "the people" and to promise voters a return to simpler days, when people "like them" were the main protagonists of national narratives, beneficiaries of economic mobility, and members of stable ethnic, racial, and religious majorities (Steenvoorden and Harteveld, 2018).

Despite the recognition of nostalgia's importance in contemporary politics, relatively little is known about the specific discursive forms it takes, its relationship to other frames commonly associated with the radical right (i.e., populism, nationalism, and authoritarianism), and its prevalence outside of radical politics. This suggests a series of unresolved questions. Do politicians weave rich accounts of bygone historical moments or rely on less specific evocations of collective loss? What domains of political life are seen to be declining and how does this vary across speakers' political ideology? Does nostalgia reinforce populist anti-elite claims and is it directly linked to social exclusion (e.g., via concern over eroding ethnoracial hierarchies)? Is nostalgic discourse solely a radical strategy or is it also commonly observed in the political mainstream? Finally, if it is the latter, under what circumstances might mainstream political actors be inclined to rely on this form of political talk?

We explore these questions by analyzing the campaign speeches of Democratic and Republican candidates in U.S. presidential elections between 1952 and 2020, including the 2016 and 2020 radical-right campaigns of Donald Trump. We train a computational language model that identifies instances of nostalgia in these texts, allowing us to examine the content of this frame and measure its prevalence over time and across campaigns. We find that nostalgia is a persistent feature of U.S. politics among candidates from both parties. Most nostalgic appeals, however, do not consist of rich accounts of a lost golden age. Instead, they take the form of succinct statements promising to reclaim some element of the past, with their typical lexical signature involving "re-" verbs (e.g., "return", "restore", "rejuvenate") or the use of the adverb "again." Trump's "Make America Great Again," therefore, was less a departure from the mainstream than an adaptation of existing rhetorical strategies.

Our results also confirm that nostalgia is a strategy used by challengers from both parties to delegitimize the political establishment. As such, it functions in tandem with populism, as confirmed by a high within-speech correlation between these two frames. This does 
not imply however that both parties idealize the same aspects of the past. We show that Democrats' nostalgia tends to focus on investments in infrastructure and education, whereas Republicans more commonly use it to discuss the failures of government, national values, and foreign policy. Finally, there appear to be broad temporal patterns in the use of nostalgia, with the 1950s and 1990s marking its low points. Though we hesitate to make too much of a finding based on only seventeen time points, one possible interpretation is that periods characterized by acute social change, particularly related to race, immigration, war, and government corruption, like the 1960-70s and 2000-10s, may create greater incentives for candidates to appeal to voters on the basis of a lost past that is idealized as more stable and harmonious.

\section{Nostalgic Appeals in Radical-Right Discourse}

In an effort to understand the mechanisms driving support for the radical right, scholars have become increasingly interested in the content of parties' and candidates' discourse (Hawkins et al., 2018). This growing body of literature commonly identifies three core supply-side features of radical-right politics: populism, exclusionary nationalism, and authoritarianism (Bonikowski, 2017; Rooduijn, 2014; Rydgren, 2005). Combining these frames into a powerful mobilizing formula, radical-right actors routinely vilify elites as morally corrupt and having abandoned the interests of "the people" for their own nefarious ends and the appeasement of immigrants and ethnic, racial, and religious minorities (Mudde, 2007). The solution to this problem is the replacement of the establishment with the people's rightful leaders, who will use any means necessary to prevent the nation from slipping further in the direction of cosmopolitanism, liberalism, and multiculturalism (or more recently, "wokeness").

As a growing body of research documents, the appeals of radical-right actors are not limited to a critique of the present and the promise of a better future: they also prominently feature an idealized notion of a forsaken collective past (Betz and Johnson, 2004; Duyvendak, 2011) - that is, they evoke collective nostalgia. This framing device adds a powerful affective dimension to radical-right mobilization because it evokes a sense of loss and engenders a yearning for national restoration (Elgenius and Rydgren, 2019; Sedikides et al., 2015). Nostalgia, however, is not merely an affective gloss atop the radical right's core message - it is itself an indispensable feature of that message. We argue that this is so for two reasons.

First, nostalgia may bind together populist, nationalist, and authoritarian frames into a coherent and actionable imperative. The elites are corrupt, according to the narrative, but they were not always so; they have lost their way over time because they lack a moral compass, but also because they have been co-opted by minority-serving special interest groups. Those minorities - whether immigrants, refugees, Muslims, or African Americans - demand ever-greater rights to the detriment of the majority, according to right-wing discourse, but this too was not always the case: the nation used to belong to white Christians, who unquestionably dominated economic, political, and cultural spheres (Whitehead and Perry, 2020; Gorski and Perry, 2022). In other words, there once was a time when "the people" (typically meaning non-whites) "knew their place." Nostalgia is therefore a story of collective decline- 
of a nation on the wrong path. And if the past was indeed better than the present, then there is cause for optimism. The clock can be turned back and the golden era can be restored by "the people's" true champions who have sufficient resolve to wrest power away-by force, if necessary - from the corrupt elites and their minority supporters.

This integrative function of nostalgia points to its second feature: it may help activate the white majority's out-group resentments by highlighting shifts in the relative positions of racial and ethnic groups within the nation's status hierarchy (Bobo, 1999), and particularly, the potential loss of dominant status by the white majority (Smeekes et al., 2015). As scholars have documented, increasing the salience of demographic change, for instance, heightens whites' perception of status threat (Abascal, 2020; Craig and Richeson, 2014; Danbold and Huo, 2015; Outten et al., 2012), thereby bolstering their support for radical-right movements and candidates (Bai and Federico 2021; Major et al. 2018; Willer et al. 2016; but see Stewart and Willer 2021). The anticipation of further decreases in the group's numerical majority has an implied temporal converse: in earlier historical periods, whites' dominance was less tentative. This sense of historical decline engenders resentment toward minority groups and is easily cued by appeals to a lost past (Elgenius and Rydgren, 2019; Smeekes et al., 2015).

The power of nostalgia also rests on the indeterminate manner in which it is often deployed in political discourse (Karakaya, 2020). When Donald Trump admonished voters to "Make America Great Again," he did not paint a vivid picture of the past that has been lost. He did not explicitly reference whites' once unquestioned dominance, nor did he specify the historical period when America had been great. Instead, he signaled a vague and multivocal nostalgic sentiment, into which the audience could impute their own preferred meanings. Given that Trump's discourse was broadly exclusionary, it is not surprising that many of his supporters interpreted the glorified past in racial and religious terms (Whitehead and Perry, 2020). Others, however, may have viewed the campaign slogan in primarily economic terms, yearning for times of greater intergenerational mobility or more stable employment in domestic manufacturing (Gest et al., 2018), while others yet perceived the slogan through a national security lens, hearkening for a time of foreign policy isolationism, geopolitical dominance, and freedom from threats of domestic terrorism.

The inherent multivocality of thin nostalgic rhetoric not only makes it broadly appealing across a wide range of audiences, but it also gives ethnonationalist supporters - and radical-right politicians themselves - plausible deniability against accusations of racism or xenophobia. Although some are likely to be unabashed in their exclusionary views, others may prefer to retain the appearances of respectability in a society where racism typically takes on a laissez-faire or colorblind rather than explicit form (Bobo et al., 1997; BonillaSilva, 2006). In this sense, nostalgia can serve as a dog-whistle strategy (Bonikowski and Zhang, 2019; López, 2015; Wetts and Willer, 2019), whereby the reference to a lost past appears innocuous on its face, but has a clear exclusionary meaning for those who share the speaker's ethnonationalist predilections. 


\section{Mainstream Antecedents of Radical-Right Frames}

Although growing scholarly attention to nostalgic political discourse has been primarily motivated by an interest in radical-right mobilization, it is likely that this form of claims making is limited neither to radical parties nor the right. Recent studies have shown populism and authoritarianism - two other central components of radical-right appeals - to have a long history in mainstream U.S. politics (Bonikowski and Gidron, 2016; Bonikowski et al., 2021). Given the ubiquity of nostalgia as a basic human emotion, its efficacy as a political framing device, and the simple ways in which it can be evoked, we should expect it to follow a similar trajectory from the mainstream to the extreme.

The question of the distinctiveness of radical discourse is of central importance to scholarship on political culture. Given the steady mainstreaming of radical-right parties and candidates over the past two decades, it is tempting to see them as having invented a new form of politics. If most of their frames, however, are in fact borrowed from mainstream politics, this would suggest that the seeds of radicalism had been sown long before. If so, this need not imply there is nothing new in radical-right discourse - the recombination of existing frames may be an innovation in its own right-but it would warrant greater attention to the antecedents of radicalism and the connections between mainstream and radical frames.

Moreover, if radical frames echo claims made by mainstream political actors, it may be the case that mainstream politicians, often unintentionally, amplify the resonance of the radical discourse. In some cases, this may take the form of an opportunistic flirtation with nostalgia-fueled populism, ethnonationalism, or authoritarianism, as in the center-right's long-standing use of dog-whistle appeals to white supporters' racial resentment (Bonikowski and Ziblatt, 2020). In other cases, the content - whether explicit or implicit - of mainstream nostalgic frames may be unrelated to or even contradictory of their radical-right's variants, but these frames' usage is likely to legitimate their formal properties, making their subsequent adoption by radical actors more resonant. In either scenario, the efficacy of radical-right discourse could be seen as an unintended consequence of its mainstream antecedents.

There is also a practical benefit to studying mainstream variants of radical frames. Despite the (uneven) successes of radical-right parties and candidates, their presence in electoral politics - and all the more so in government - has been relatively short-lived in all but a few countries. As a result, the number of available data points for examining the variation in radical-right discourse is limited. In contrast, if comparable frames are present in mainstream discourse, the temporal and comparative scope of the investigation can be expanded, thereby enabling systematic inquiry into the dynamics of and interconnections between frames that have been adopted by radical actors. This, of course, does not preclude the possibility that the process of adoption by the radical right was also one of adaptation, so direct inferences about radical politics on the basis of mainstream discourse must be made with caution.

Finally, it is important to emphasize that similarity of discursive form does not imply similarity of normative implications: the objectives of radical-right actors and the dangers their discourse, policies, and governance pose to liberal democracy are not comparable to those of mainstream actors - or for that matter, radical-left parties and candidates. Our goal 
in this paper, therefore, is to engage in genealogical inquiry and analytical comparison, not to make claims of moral equivalence.

\section{Theoretical Expectations}

Guided by the above considerations, our study focuses on the use of nostalgia in Democratic and Republican presidential campaigns between 1952 and 2020, of which two-Donald Trump's 2016 and 2020 campaigns - can be reasonably classified as radical right. We are interested in six main questions, which we enumerate below. Although our expectations are not sufficiently strong to yield formal hypotheses, we suggest some possible findings based on our reading of the literature on political framing in mainstream and radical campaigns.

First, we ask the simple descriptive question whether nostalgia is present throughout the time series and if so, how commonly it occurs. We anticipate finding ample evidence of its use by candidates prior to Donald Trump, but whether Trump's routine use of "Make America Great Again" and related tropes made him an outlier compared to his mainstream predecessors is less clear. It is possible that although Trump did not invent political nostalgia, he made especially frequent use of it, all the more so given that this framing was incorporated into his very campaign slogan. Alternatively, we may find that the Trump campaign was unremarkable in its declinist rhetoric, even if other candidates relegated this framing to the content of their speeches instead of their campaign taglines.

Second, to the extent that nostalgia had been present in U.S. politics over the 69 years covered by our data, was its use patterned by period effects? That is, did certain events in post-war U.S. history create greater or lesser incentives for politicians to rely on declinist narratives? The set of possible causes for the kind of national pessimism that would serve as fertile ground for nostalgia is large - ranging from economic recessions to natural disastersand the number of data points at our disposal is limited, so a formal test of period effects is not feasible. Given our arguments, however, about the role of nostalgia as a potential dog-whistle for ethnoracial conservatism on the right - and possibly as a left-wing counternarrative that appeals to the nation's historic "better angels" (Wohl and Stefaniak, 2020) we are especially interested in whether periods of widespread cultural conflict are associated with greater reliance on declinist claims. In particular, the three waves of white backlash (Hughey, 2014) - against Civil Rights in the 1960s and 1970s, affirmative action and "identity politics" in the 1990s, and the election of the first Black president in the 2010s - as well as reactions to perceived governance crises, such as the Vietnam War and Watergate, may be particularly relevant when examining our time series.

Third, in probing the manifestation of nostalgic claims, we are interested in whether they typically consist of rich accounts of specific periods in the country's history or whether they take the form of brief statements with unclear historical referents, akin to Donald Trump's "Make America Great Again." This is relevant because it may allow us to identify continuities and divergences between mainstream and radical variants of nostalgia, but also because it can illuminate how nostalgia functions in practice. A more elaborate account of the past may be more evocative and therefore more compelling for its intended core audience, but 
it risks alienating those who do not share the same commitments or cannot relate to the specific period in question. Effectively, such accounts risk being too specific. On the other hand, brief references to an undefined past may be less direct and evocative, but they have the virtue of being multivocal and veiled, potentially appealing to a wider range of audiences (Karakaya, 2020). We do not have clear expectations on which form is likely to be more common.

Fourth, in addition to examining aggregate patterns in the use of nostalgia, we also focus on differences in the prevalence and content of nostalgic claims across the two parties. The potential use of nostalgia as a dog whistle for ethnonationalism would suggest that Republicans should be especially likely to use it. At the same time, the ideological flexibility of nostalgic claims and their resonance with basic human emotions (Sedikides et al., 2008) may lead Democrats to employ them as well, to promote their own policies and possibly to contest the visions of the past offered by their Republican counterparts (Wohl and Stefaniak, 2020). If so, it is possible that both parties will rely on nostalgia, much as both parties frequently use populist claims (Bonikowski and Gidron, 2016). Nonetheless, we expect the two parties to differ in terms of which specific policy domains they frame in nostalgic terms.

Fifth, if nostalgia is not the exclusive province of either party, this raises the question of what - besides possible period effects - explains its between-campaign variation. One possible mechanism is the speaker's incumbency status. Critiques of the status quo are much riskier for incumbents (or nominees of the incumbent party), because these actors are seen as responsible for the country's ongoing fortunes. Challengers, in contrast, only stand to gain from criticizing the state of the country, because by doing so, they also undermine their incumbent opponents (Crabtree et al., 2020). This is a dynamic that has been documented for populist claims (Bonikowski and Gidron, 2016; Dai and Kustov, 2021; Fahey, 2021) and it may be relevant for nostalgia as well, since both frames paint the present in a negative light. The transition between Donald Trump's 2016 slogan "Make America Great Again" and its non-nostalgic, and arguably less compelling, 2020 variant "Keep America Great" is case in point.

Sixth, our study examines the relationship between nostalgia and other frames commonly associated with radical-right discourse, including populism, exclusionary nationalism, and authoritarianism, as measured in our recent study using the same corpus (Authors 2021). This follows from our earlier argument that nostalgia may serve as a mechanism connecting these discursive elements. Our expectations for populism are the clearest: in light of the common critique of the political status quo inherent in nostalgic and populist claims, these two frames should be positively correlated in campaign rhetoric (Kenny, 2017). The same is likely to be true of exclusionary nationalism (though its prevalence in mainstream political speeches is low [Authors 2021]) and authoritarianism, as the latter may function as a dog whistle for nationalist exclusion. Another dimension of nationalism that may be associated with nostalgia is low pride in the nation - this frame has been found to be highly correlated with populism in the past and it bears a close resemblance to nostalgia: it involves negative judgments about the present, though not necessarily accompanied by the glorification of the past. 
Our expectations for the obverse frames with respect to exclusion and low pride are less clear. Inclusive nationalist frames may be associated with nostalgia if the latter is used to counteract right-wing exclusionary claims, but it may also be the case that inclusive arguments are typically made without appealing to a better past, given that the United States' historical record of racial oppression limits the range of positive experiences to draw on (the Reconstruction and Civil Rights eras notwithstanding). Finally, expressions of strong national pride should be more weakly associated with nostalgia than is the case for low pride, given that the former consists of a celebration of the nation's accomplishments. Yet, to the degree that high pride emphasizes timeless national values, it may occasionally co-occur with declinist narratives about the nation wavering from its historical commitments.

By analyzing the relationships between nostalgia and populism, nationalism, and authoritarianism, we are also able to engage in direct comparison between mainstream and radical campaigns. Even if the formal properties of nostalgia were to be similar across the two types of campaigns, the way in which mainstream and radical actors combine nostalgia with other frames may differ. If so, this could give us insight into how radical actors creatively recombine existing discursive elements as they craft their appeals to disaffected voters. Moreover, such an analysis can effectively test our earlier arguments about the role of nostalgia in radical-right mobilization: if nostalgia does fuse and amplify the radical right's constitutive frames, as we had claimed it may, we should expect to observe strong associations between these discursive strategies in Donald Trump's campaign speeches.

\section{Data}

To examine these questions we draw on a corpus of presidential nominee speeches collected from two sources: the Annenberg/Pew Archive of Presidential Campaign Discourse (Annenberg, 2000), which covers the twelve presidential elections between 1952 and 1996, and the UC Santa Barbara American Presidency Project (UCSB, 2021), which spans the six elections between 2000 and 2020. We limit our analysis to speeches given by the two parties' nominees between September 1 and Election Day, as well as their nomination acceptance speeches, in line with the constraints of the Annenberg data. Transcripts of debates, ads, and town halls are excluded from the corpus. In addition, the Annenberg database does not include speeches from the 1964 Goldwater campaign, whereas the UCSB Project lacks speeches from the 2000 Bush campaign; consequently neither campaign is included in our analyses. The final corpus consists of 2,795 speeches split into 70,396 paragraphs.

The corpus metadata we employ in our analyses include the year in which the speech was given and the speaker's party. We also compiled information on whether or not the speaker's party held the presidency during the election and whether or not the speaker was a president running for re-election or had served as president in the past. These two variables allow us to examine the association between incumbency status and the use of nostalgia. Descriptive statistics for the corpus are reported in appendix A. 


\section{Measuring Nostalgia with Transformers and Active Learn- ing}

To measure nostalgia, we rely on recent advances in supervised machine learning, and specifically the use of transformer-based models. We first drew a random sample of 2,000 paragraphs from the data and annotated them with regard to whether they contain nostalgic claims. To maximize the efficiency of this process with limited resources, both authors individually annotated 1,250 paragraphs, resulting in a sample of 500 doubly annotated paragraphs. Cohen's Kappa for these annotations was .68, suggesting substantial but imperfect inter-rater reliability. Any disagreements in the 500-paragraph sample were then resolved in discussion. We use these 500 paragraphs as our test sample, leaving a training sample of 1500 singly-annotated paragraphs. Only 2.7 percent of these paragraphs contained nostalgic claims, making nostalgia a rare feature and therefore a difficult phenomenon to classify for any computational model.

For our classification, we deployed a customized deep neural language model. Specifically, we use the robustly optimized BERT-pretraining approach (RoBERTa) by Liu et al. (2019), which is part of a broader class of models known as transformers. Since their introduction (Vaswani et al., 2017), transformer-based models have revolutionized natural language processing by vastly outperforming other model families on a wide variety of tasks. ${ }^{1}$

Models like RoBERTa are pre-trained on large volumes of text to solve general language tasks, such as predicting the next sentence given an input text sequence or predicting a randomly masked word in a text sequence. From these generic tasks, the models develop knowledge about not just the meaning of words but also about the subtle workings of a language. This information is contained in the models' weights - the RoBERTa model we use, for instance, is a deep neural network with 125 million parameters that encode relational knowledge about the English language. The trained versions of these models are made publicly available for application to a wide range of applications, including classification.

Perhaps the most intuitive way to use RoBERTa for a classification task like ours would be to pass our paragraphs through the model and use the vector representation so generated in a conventional classifier. For better results, however, it is more common to append a classification layer to RoBERTa that is specific to the problem at hand; here, distinguishing paragraphs that contain nostalgic claims from ones that do not. In a process called "finetuning," this involved training the model for a small number of additional epochs on the manually annotated training data. In the process, the weights of the language model are adjusted via "backpropagation," as is common for neural network classifiers. Instead of a general language model, RoBERTa then becomes a language model specialized in identifying nostalgic claims. Contrasting our approach with conventional, document term matrix-based methods one might say that instead of teaching a model what nostalgia is and how to speak English at the same time, we are teaching a model that already speaks English to identify nostalgia.

\footnotetext{
${ }^{1}$ The architecture of these models lies beyond the scope of our paper. For social science-oriented introductions, see Terechshenko et al. 2020; Bonikowski et al. 2021; Jensen et al. 2021.
} 
Figure 1: Performance of RoBERTa classifier and top features
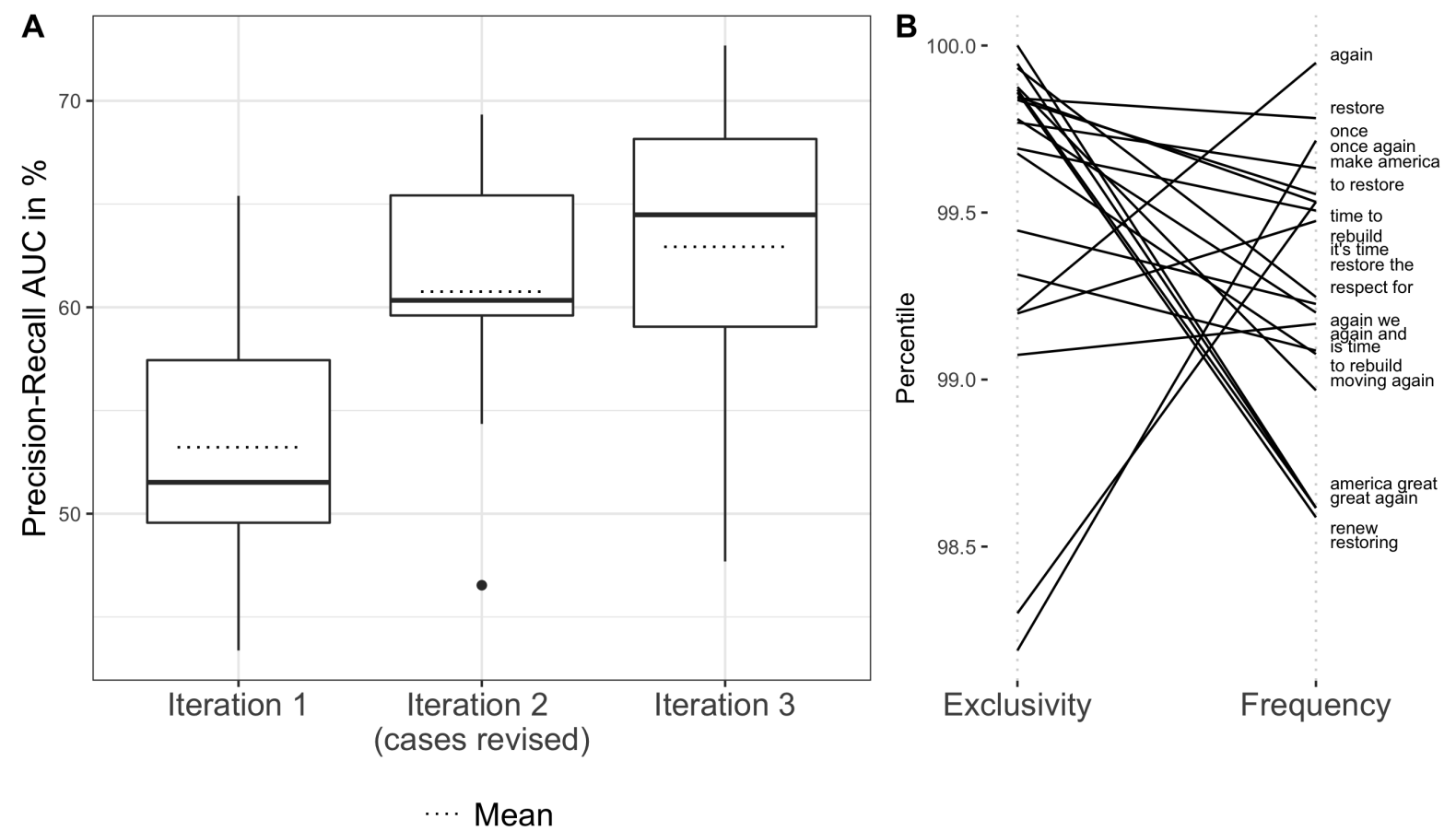

When it comes to model evaluation, the imbalance of the categories of interest in our data, stemming from the rare occurrence of nostalgia, makes classic measures like accuracy or the area under a receiver operator characteristics curve (ROC-AUC) relatively uninformative and potentially misleading. Consider that by default, we could achieve an accuracy of .97 by simply labeling all paragraphs as not nostalgic. We therefore evaluate our models' performance using the area under the precision-recall curve (PR-AUC), as is common practice for highly imbalanced datasets (Saito and Rehmsmeier, 2015). PR-AUC effectively sorts the test set documents by the predicted probability of their containing nostalgia and computes model precision and recall values at a range of possible cutoff thresholds. A model with perfect precision and recall would achieve a PR-AUC of 1 , while the theoretical baseline of the measure (for a classifier with no skill) is equal to the prevalence of the feature to be predicted-.027 in this case.

As a first step, we split our training sample into 10 folds and train 10 models with one held out subset. This allows us to get predictions for each of our training cases but also for our doubly-annotated, 500-case test set. The first boxplot in panel A of figure 1 shows the distribution of PR-AUC values as evaluated against the test set. On average, our models achieve a PR-AUC of .53 which is considerably higher than the theoretical baseline.

To improve these predictions, we build on active learning, another innovation in machine learning that has recently gained popularity (Dor et al. 2020; for applications, see Bonikowski et al. 2021; Dai and Kustov 2020). Active learning involves an iterative process, whereby the machine learning classifier identifies ambiguous texts, which are then hand-coded by the 
researcher and returned to the training set, thereby (ideally) improving the model's accuracy in a subsequent round of training and classification. In our case, we used the predictions made for our singly annotated training set and collectively hand-coded the 150 cases with the highest uncertainty (a prediction close to .5 for both classes). This led us to revise 25 of our initial labels. Next, we again divided our training data into folds and ran 10 models, then evaluated their predictions against the test set. This resulted in an average PR-AUC of .61-a substantial improvement over our first run (shown as "Iteration 2" in figure 1, panel A). Finally, we used these 10 models to generate predictions for the unlabeled data, and selected the 300 cases associated with the greatest ambiguity. The idea here was, again, to provide the model with cases that were particularly helpful in resolving its uncertainties. We annotated these data and added them to the training set, leading to a training sample size of 1,800 cases. We then repeated the process of running 10 models with random splits of our training data, yielding a more marginal improvement in average PR-AUC of .63.

Finally, we use each of these models to generate nostalgia predictions for the whole corpus and average these predictions for each paragraph. For the purpose of our analyses, we consider precision to be more important than recall - that is, we think it is more important to ensure that the cases we label as nostalgic are actually nostalgic than to find all nostalgic cases. Accordingly, instead of considering any paragraph with a predicted probability greater than .5 to be nostalgic we increase this threshold. To find an appropriate predicted probability threshold, we set a precision target of .8 and average the thresholds that would have been sufficient to achieve this within our test set, given the predictions of the models we trained. The expected recall at these thresholds is .4. Intuitively, this means that out of every 5 cases we label as containing nostalgic claims, we expect 4 to be true positives. On the other hand, we expect to capture 2 out of 5 paragraphs containing nostalgic claims.

Although the performance of our classifier is not perfect, we believe it to be sufficient, especially given the complexity and rarity of the underlying phenomenon. In this context, it is important to keep in mind that agreement among highly trained human coders (the authors) was itself imperfect (and would likely further decrease if the task was expanded from the coding of a sample of paragraphs to that of the entire corpus), and that classification error, under the assumption of randomness, is likely to attenuate any patterns we identify in our analyses. Furthermore, we show in appendix $\mathrm{C}$ that our findings are robust to variation of the classification cutoff value (that is, to higher recall and lower precision values). As is often the case with computational methods, modest limitations in accuracy are outweighed by the ability to systematically and efficiently analyze large volumes of text (in this case, 70,396 paragraphs) and to use these results to identify substantively and theoretically meaningful patterns and associations. 


\section{Results}

\section{Formal Properties of Nostalgic Frames}

We begin with an examination of what nostalgia looks like in U.S. presidential election discourse. On average, this frame occurs in about 2.8 percent of paragraphs per campaign $(\mathrm{SD}=2.3)$. Figure 1 Panel $\mathrm{B}$ shows the twenty most characteristic unigrams and bigrams in nostalgic paragraphs ${ }^{2}$ : "restore" (and "to restore"), "once," "again," (and "once again"), "time to," and "rebuild" are among the most frequent. Among the features that are most exclusive to nostalgic paragraphs are "restoring," "renew," "great again," and"moving again." This suggests that nostalgic frames have a distinctive lexical signature, often marked by the use of the adverb "again" and verbs beginning with the prefix "re-," both of which evoke a return to the past.

Is nostalgia limited to brief utterances invoking a vague past or does it consist of rich descriptions of specific historical periods? The features identified above suggest that nostalgic claims follow a consistent sentence-level form, but it is possible that references to "restoring" the past or returning to it "again" are couched within more richly descriptive paragraphs. A close reading of these texts - carried out both in the course of annotation and post-classification validation - suggests otherwise. In the vast majority of positive cases we reviewed, nostalgic content is limited to a single sentence containing the kinds of terms identified in figure 1, panel B.

Consider the following excerpt from Bill Clinton's 1992 nomination acceptance speech:

We can seize this moment, we can make it exciting and energizing and heroic to be an American again. We can renew our faith in ourselves and each other, and restore our sense of unity and community.

The common lexical signature of nostalgia is clearly visible in the use of "to be an American again" and the verbs "renew" and "restore." The national qualities that allegedly have been lost are the sense of excitement, energy, and heroism in being American, faith in the collective, and a sense of community. At no point in the surrounding paragraph, however, did Clinton specify the historical period when these qualities were more dominant, nor what implications this had for the country's fortunes at the time. Like most instances of nostalgia in the corpus, the reference to a lost past is brief, unspecific, and multivocal.

Similar rhetoric is found in the following passage from a 1980 speech by Ronald Reagan:

I do promise to renew the bond between the presidency and the people, forever conscious that the office of the president is a sacred trust. I do not couch my promises in high-sounding rhetoric. I promise simply that America will be able to hold its head up again.

\footnotetext{
${ }^{2}$ These features were selected according to a frequency-exclusivity score. The score is the mean of a feature's $\left(w_{i}\right)$ rank by probability within nostalgic paragraphs, that is $P\left(w_{i} \mid\right.$ Nostalgia $)$; and its rank by exclusivity within nostalgic paragraphs, where exclusivity is defined as the probability of a paragraph being nostalgic given the observation of the feature $P\left(\right.$ Nostalgia $\left.\mid w_{i}\right)$.
} 
Here too the verb "renew" and adverb "again" do most of the semantic work, suggesting that at some undefined point in the past America had been able to hold its head up, due to a bond between the presidency and the people, but that this is no longer the case. As in the Clinton passage, Reagan situates himself as the one who is able to restore the country to this idealized prior state.

We see analogous patterns in the following four quotes by Adlai Stevenson (1956), Walter Mondale (1984), Barack Obama (2012), and Donald Trump (2016), respectively.

America must return to the basic principles in which the nation believes. First of all, we must rededicate ourselves to our faith in democracy and make that faith a living principle.

- Adlai Stevenson (1956)

We need to make America once again a beacon in the world. We need to be looked up to and not just feared.

- Walter Mondale (1984)

The values of hard work and personal responsibility and looking after your neighbor, those aren't just values of rich folks or poor folks or the 1 percent or the 99 percent. They are American values, and they belong to all of us. And if we reclaim those values now, if we rally around a new economic patriotism together, we can rebuild this economy together.

- Barack Obama (2012)

A failed political establishment has delivered nothing but poverty, nothing but problems, nothing but losses. Nothing but losses. We don't win anymore as a country. We're going to start winning again.

- Donald Trump (2016)

All four passages evoke a sense of loss - of shared values, of global leadership, or of "winning"- that can be reversed if the candidate is elected (implicitly in the first two passages and explicitly in the latter two). None of them, however, specify exactly when things were better or why this was the case. There is also no specific plan for how the past glory will be restored. And yet, this does not undermine the passages' rhetorical power. On the contrary, it is their brevity that makes them so poignant. By activating a sense of yearning for a lost past that is a common feature of human psychology (Sedikides et al., 2015), they build an affective connection between the speaker and the audience and generate a sense of collective crisis that must be addressed if future generations are to be better off than their predecessors (Smeekes et al., 2015).

The indeterminate nature of nostalgic claims also allows listeners to insert their own personal concerns into the narrative of decline. No longer being a beacon of the world, no longer abiding by the principles of democracy or values of hard work, personal responsibility, and communal support, and no longer "winning" can be a result of any number of economic, 
Figure 2: Use of nostalgia by election, 1952-2020

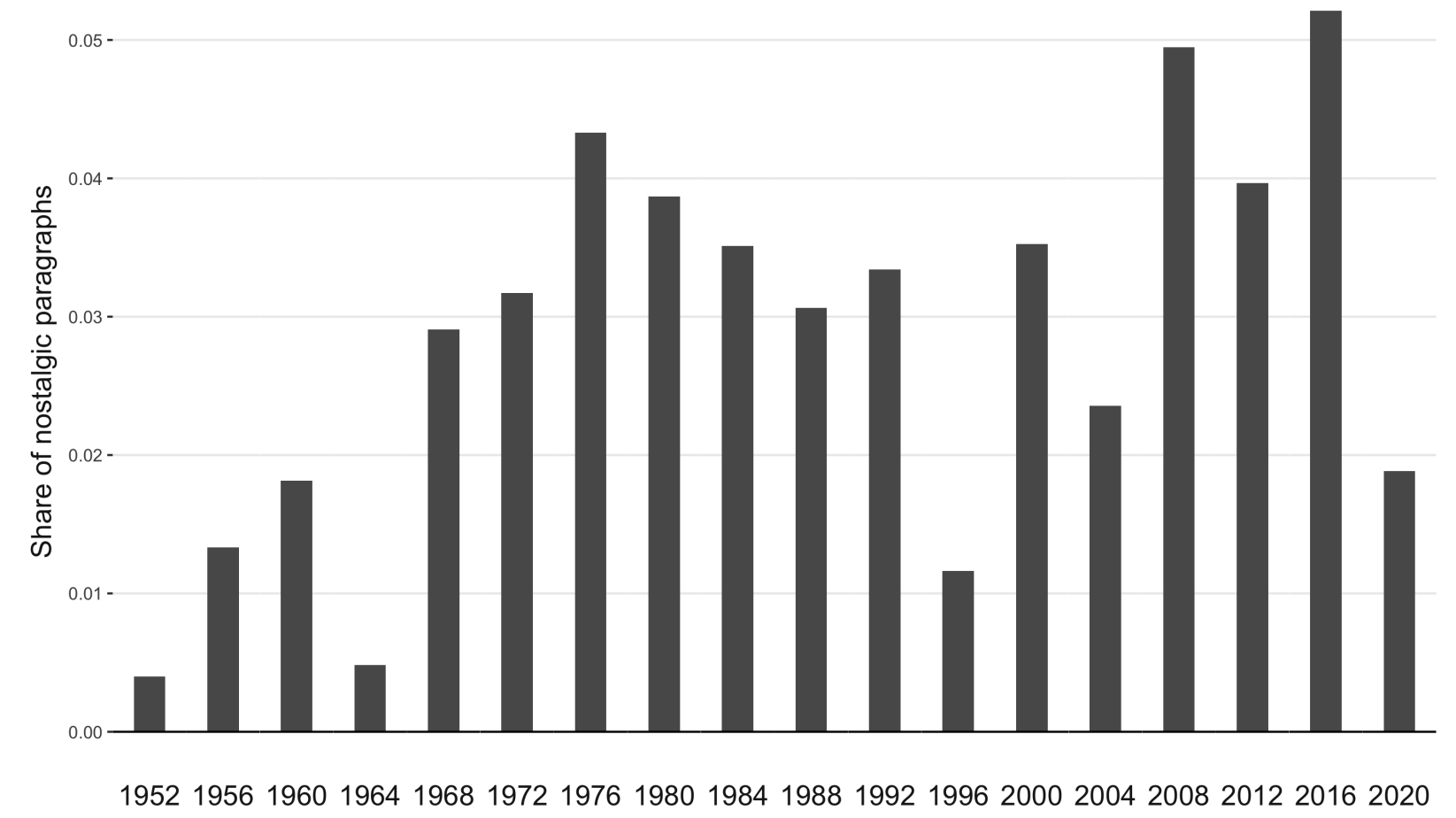

political, or cultural changes, from economic inequality to government overreach, from insufficiently progressive policies to the erosion of traditional social (i.e., racial, ethnic, religious, or gender) hierarchies, or from elite corruption to partisan demagoguery. In easily accommodating a wide range of grievances, nostalgic claims are inherently multivocal and therefore potentially appealing to a wide range of voters who may disagree about the importance of specific issues but share a common concern with national decline.

\section{Nostalgia Across Eighteen Presidential Elections}

The above examples span multiple elections and are drawn from both parties. But how prevalent was nostalgia prior to the 2016 election, when Donald Trump made such effective use of it? To answer this question, figure 2 illustrates the share of nostalgic paragraphs across the eighteen elections covered by our corpus. Not surprisingly, the 2016 Trump-vs.Clinton contest stands out as the high water mark for the use of nostalgia, with 5.2 percent of the two candidates' paragraphs (averaged across the campaigns) featuring appeals to a lost past. Donald Trump's nostalgic campaign slogan, "Make America Great Again," which he frequently mentioned in his speeches, certainly contributed to this pattern. ${ }^{3}$ And yet, the 2016 election was hardly unusual in its nostalgic content. Nostalgic claims were nearly

\footnotetext{
${ }^{3}$ When we remove paragraphs containing Trump's slogan from the analysis, the share of nostalgic paragraphs for that election decreases to 4.5 percent.
} 
as common in the 2008 election (at 5 percent) and also reached high levels of prevalence in the 1976, 1980, and 2012 elections (at 4.3, 3.9, and 4 percent, respectively). Indeed, one of the takeaways from figure 2 is the presence of nostalgia in all elections covered by our time series, which confirms that this discursive form is endemic to U.S. democratic politics.

Despite nostalgia's ubiquity, however, the frequency of its usage varies over time. Conclusively explaining these patterns is difficult given the few available time points, but some conjectures are possible. Notably, figure 2 reveals two time periods that were marked by lower levels of nostalgia: the 1950s and the mid-1990s through the early 2000s. The former period corresponded to the peak of the post-war economic boom, prior to the cultural conflicts and social transformation brought on by the Civil Rights, anti-war, and women's liberation movements of the 1960s and 1970s. The latter period of dampened nostalgia was a time when the United States emerged victorious from the Cold War and experienced unprecedented economic growth amidst rapidly intensifying global integration. It appears that both of these relatively "settled" times reduced the incentives for candidates to appeal to a lost past.

We treat this conclusion as tentative, however, not least because the temporal alignment of the nostalgia downturn with historical events is not perfect. The corpus does not include the 1964 Goldwater campaign, so we cannot determine whether the onset of the Civil Rights movement resulted in a nostalgic upswing that year, whether the use of nostalgia lagged behind political-cultural shifts and became noticeable only in the 1968 election, or whether the two trends are in fact unrelated. Similarly, the low level of nostalgia during the 2004 election, which followed the September 11 attacks, is somewhat surprising. One possibility is that despite the fracturing of the post- $9 / 11$ patriotic consensus in the aftermath of the invasion of Iraq, a residual rally-round-the-flag effect (Feinstein, 2016) dampened the incentives for glorifying a lost past and instead led candidates to focus on moving the still-shaken country forward. It appears that it was not until the 2008 candidacy of Barack Obama that nostalgia returned to its historically high levels. To enable a closer interpretation of these patterns, we turn to an analysis of party-specific trends in the use of nostalgic claims.

\section{Party Differences in Nostalgic Discourse}

Figure C.3 presents the prevalence of nostalgia in each campaign, with Democratic campaigns indicated in blue and Republican campaigns in red. The first thing to notice is that the use of nostalgia is not limited to either party. Republicans far outpaced Democrats in the use of nostalgia in four elections: 1968 (Nixon vs. Humphrey), 1980 (Reagan vs. Carter), 2012 (Romney vs. Obama), and, most markedly, 2016 (Trump vs. Clinton). Democrats, in contrast, relied on nostalgia considerably more than their Republican opponents in 1972 (McGovern vs. Nixon), 1976 (Carter vs. Ford), 1988 (Dukakis vs. G.H.W. Bush), 1992 (Clinton vs. G.H.W. Bush), and 2004 (Kerry vs. G.W. Bush). Though nostalgia did not reach comparably high levels in 1960, the contrast between Kennedy's reliance on it and Nixon's lack thereof was also marked. Those standout elections aside, both parties appeared to routinely use this discursive frame, sometimes to a similar degree in a given election, as in Mondale and Reagan in 1984, Obama and McCain in 2008, and Biden and Trump in 2020. 
Figure 3: Use of nostalgia by Democratic and Republican candidates, 1952-2020

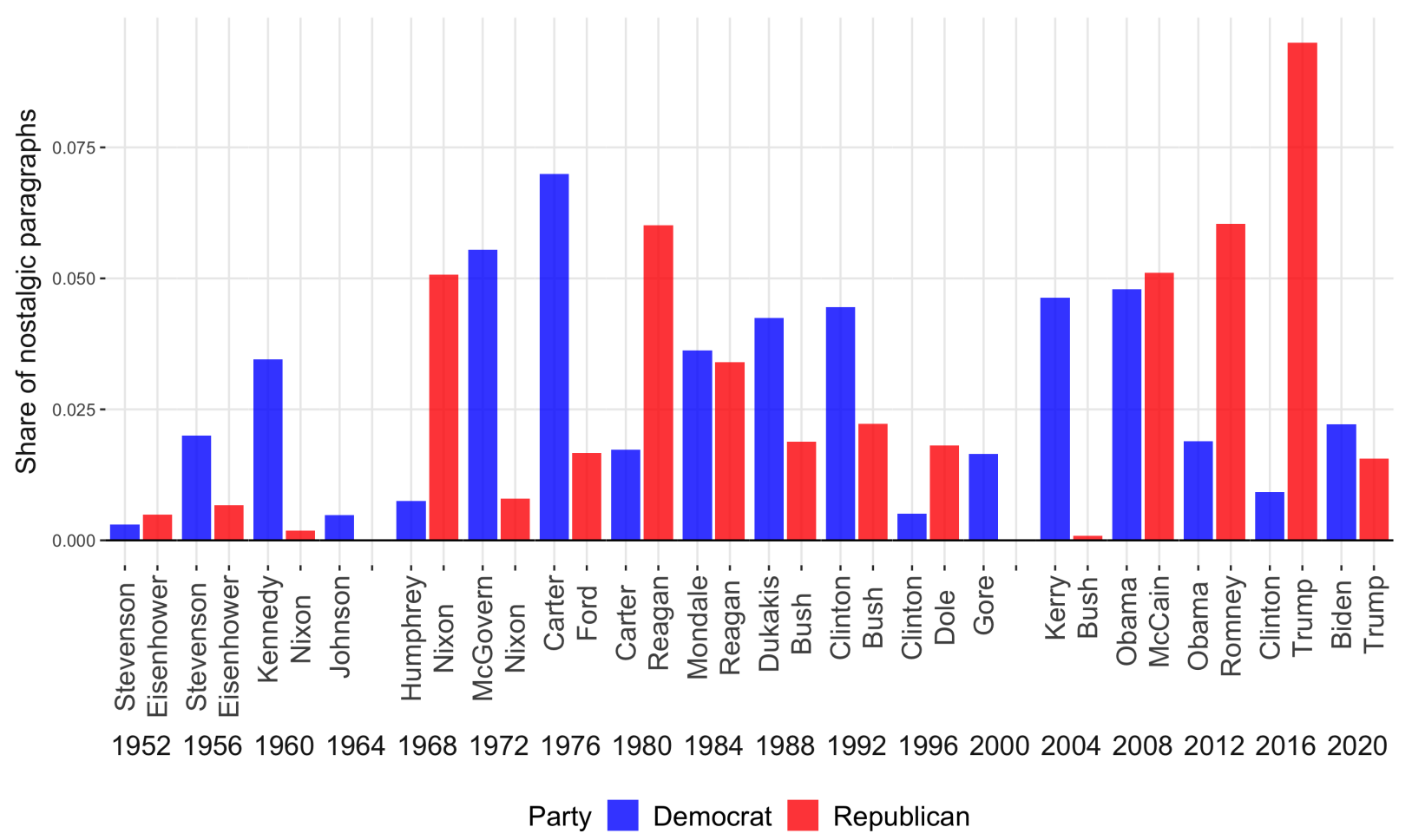

The last of those examples suggests that the nostalgia - like populism (Bonikowski and Gidron, 2016) - is less a feature of a candidate's ideology or personal style and more a deliberate strategy that can shift across a given candidate's successive campaigns. Put differently, nostalgia is a feature not of the candidate but of the campaign. Consider the difference between Trump's 2016 and 2020 campaigns. The former, built around the "Make America Great Again" theme, was by far the most notable in its use of nostalgia of all the campaigns in the time series, with the frame featured in 9.5 percent of paragraphs (far exceeding the next most nostalgic campaign's 7 percent-by Carter in 1976). By comparison, Trump's 2020 campaign used nostalgic claims in an unremarkable 1.6 percent of paragraphs. Clearly, a candidate's choice of using nostalgia is shaped by contextual conditions that are not limited to period effects - a point to which we return in the next section.

Those limitations aside, the party trends presented in figure C.3 allow us to elaborate our earlier interpretation of the temporal patterns in the aggregate time series. The first postwar campaign in our dataset to extensively use nostalgia was Nixon's in 1968 (again, we do not have data for Goldwater's 1964 run). Given Nixon's well documented reliance on subtle appeals to white racial resentment in that campaign - partly in response to George Wallace's more explicit racism - this finding has considerable face validity (Maxwell and Shields, 2019). The following example shows how Nixon used a declinist narrative to reinforce his broader message:

[...] I want the presidency to be a force for pulling our people back together once 
again $[\ldots]$. We have had enough of discord and division, and what we need now is a time of healing, of renewal, and of realistic hope.

By 1972, however, the tables had turned. Nixon was now running as an incumbent and it was his opponent, Democrat George McGovern, who sought to mobilize Americans' yearning for a lost-pre-Nixonite-past. That McGovern's campaign was also markedly populist (Fahey, 2021) suggests that populist and nostalgic frames may have reinforced one another in his campaign discourse. As the following example shows, McGovern depicted Nixon as an out-of-touch establishment figure who was blind to the myriad ways in which the country was diminishing under his leadership:

And we can put our nation on the way to enhanced national stature if we take the government out of the hands of Richard Nixon and his special interest friends and restore it to the people of America.

This pattern of incumbent-challenger alternation continued over the next two elections, with Carter's 1976 post-Watergate challenge to Ford and Reagan's 1980 neo-liberal (and racially charged, via appeals to "states rights" [Bates 2011]) campaign against Carter. Through the late 1980s and early 1990s, nostalgia was once again the province of Democratic challengers, first against Reagan and then against G.H.W. Bush, before subsiding in both parties during the relatively settled near-decade that followed. It was not until the post-9/11, postIraq-War Kerry campaign in 2004 that nostalgia re-emerged as a prominent theme in electoral discourse (a fact obfuscated in our aggregate analysis due to the absence of nostalgic appeals by the 2004 Bush campaign). This trend continued for the remainder of the 2000s and 2010s, with the 2008 Obama and McCain campaigns, the 2012 Romney campaign, and the 2016 Trump campaign all relying extensively on nostalgic frames. In 2020, however, neither the incumbent Donald Trump nor the forward-looking challenger Joe Biden reached similar heights of nostalgic claims-making.

These observations lead us toward two additional analyses. First, the examples cited above give credence to our expectation that even if both parties have frequently relied on nostalgia, they have done so in pursuit of distinct policy goals. If so, the kinds of pasts that Democrats and Republicans have sought to evoke may differ. To determine whether this is the case, we compare the content of paragraphs that feature nostalgic claims across campaigns from the two parties. Second, the party trends suggest that the use of nostalgia may be driven more by incumbent-challenger dynamics than by partisan differences. We test this possibility by regressing the campaign-specific prevalence of nostalgia on the speaker's party and incumbency status.

We begin with the analysis of the content of the two parties' nostalgic discourse. By inductively coding nostalgic paragraphs (i.e., those identified as such by our classifier), we identified six frequently occurring themes: infrastructure and education, economy and the welfare state, national values, law and order, foreign policy, and government integrity (for more details, see table B.1 in appendix B). These were sometimes evoked in the nostalgic sentences themselves, but just as often they were found in proximity to them within the same 
Figure 4: Content of nostalgic paragraphs by party

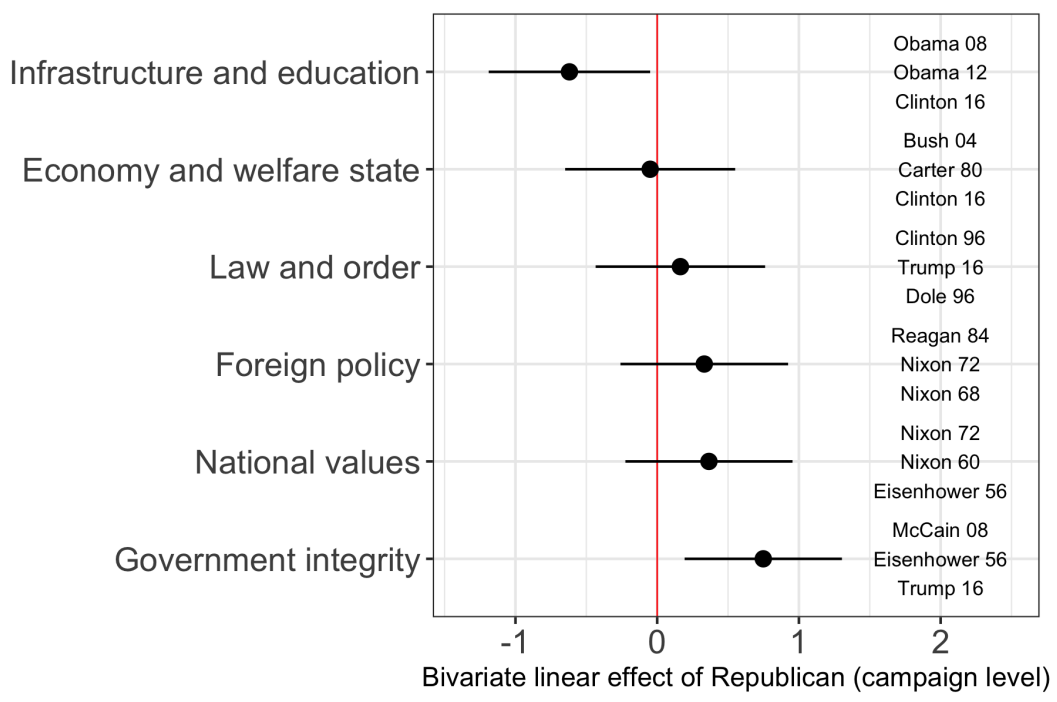

Note: Campaign-level analysis, $\mathrm{N}=33$; bars denote $90 \%$ confidence intervals; theme prevalence is measured as the share of keywords among all words contained in a given campaign's nostalgic paragraphs; Al Gore's 2000 campaign was omitted because its coverage in our data is limited to four speeches with three nostalgic paragraphs. Dependent variable is standardized.

paragraph. The findings are summarized in figure 4, which shows the association between the speaker's party and the prevalence (in standard deviations) of specific themes averaged across campaigns. It also lists the three campaigns with the highest prevalence of each theme.

Two of the topics - economy and welfare state and law and order-co-occur with nostalgia in speeches given by candidates from both parties. The former was especially prominent in the 2004 G.W. Bush, 1980 Carter, and 2016 H.R. Clinton campaigns, whereas the latter characterized the 1996 W.J. Clinton, 2016 Trump, and 1996 Dole campaigns. Two othersforeign policy and national values - are more common in Republican speeches (with all six top campaigns being Republican), but the partisan difference does not reach statistical significance (note that standard errors are large because of the small sample of 33 campaigns). Finally, the two remaining topics have a significant partisan skew. The nostalgic framing of infrastructure and education is most strongly associated with Democratic candidates (especially Obama in 2008 and 2012 and H.R. Clinton in 2016), whereas nostalgia with reference to government integrity and democratic representation is most common among Republicans (especially the 2008 McCain, 1956 Eisenhower, and 2016 Trump campaigns). These findings confirm that nostalgia can be - but is not always - used to different ends by the two parties, with the biggest differences having to do with issues related to the role of government (greater spending for Democrats and criticism of political elites, corruption, and state power for Republicans).

Next, we test the proposition that the prevalence - rather than the content - of nostalgia is less a function of partisanship than incumbent-challenger dynamics. Figure 5 presents 
Figure 5: Campaign-level predictors of nostalgia

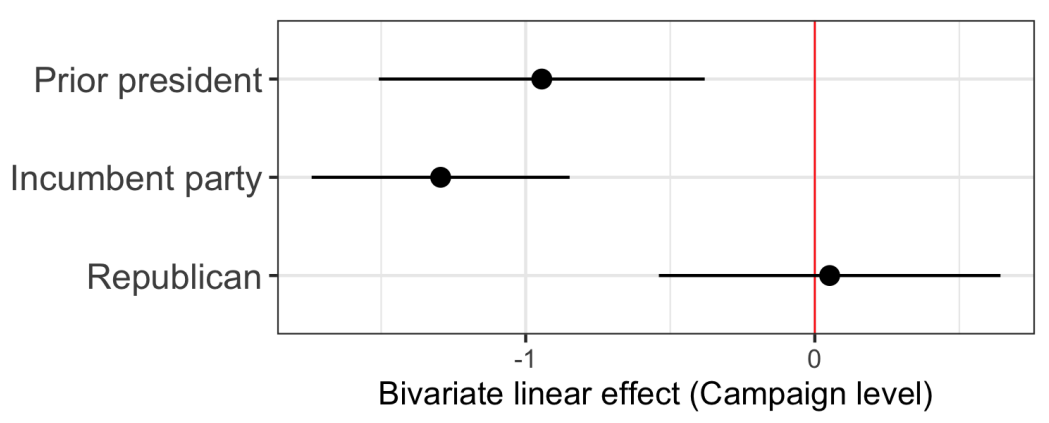

Note: Campaign-level analysis, $\mathrm{N}=34$; bars denote $90 \%$ confidence intervals. Dependent variable is standardized.

coefficients from bivariate regressions of the campaign-level prevalence of nostalgia on party affiliation and incumbency status. The results for partisanship are consistent with our expectations: Republicans were no more or less likely than Democrats to use nostalgia in their campaign speeches. Both measures of incumbency, in contrast, are strongly negatively correlated with the use of nostalgic frames. The coefficients suggest that the share of paragraphs containing nostalgic claims was 1.29 standard deviations lower for incumbent party nominees, and .94 standard deviations lower for speakers who had previously served as president.

The results thus far suggest that nostalgia is neither a trait of specific candidates nor the province of a particular party. Instead, it appears to be a common strategy of challengers from both parties, who presumably use it to undermine the accomplishments of their incumbent opponents. If the audience can be convinced that the nation is on a downward trajectory, it then becomes possible to place the blame for the decline on the current administration or governing party.

As both the aggregate and party-based analyses show, however, not all historical periods appear to lend themselves equally to nostalgic discourse. This strategy was less prevalent in the 1950s and 1990s, when U.S. political culture was relatively "settled." In contrast, during the 1960s through the 1980s and later the mid-2000s through 2016, challengers (and occasionally incumbents) had greater incentives to appeal to voters' shared sense of a lost past. These were times of heightened demand for equal rights based on race, gender, and sexuality - and of white, patriarchal, and homophobic backlash against them-as well as of opposition to wars, frustration with Watergate-era government corruption, and later, fantasies of a post-racial society inspired by Barack Obama's election, foiled by an ethnonationalist counter-movement culminating with Donald Trump's 2016 victory. In other words, these were periods of cultural turmoil that made candidates from both parties reliant on depictions of a more stable past and a brighter future - whether in the interest of egalitarian and democratic progress or racial and authoritarian retrenchment. 
Figure 6: Nostalgia's association with populism, nationalism, and authoritarianism
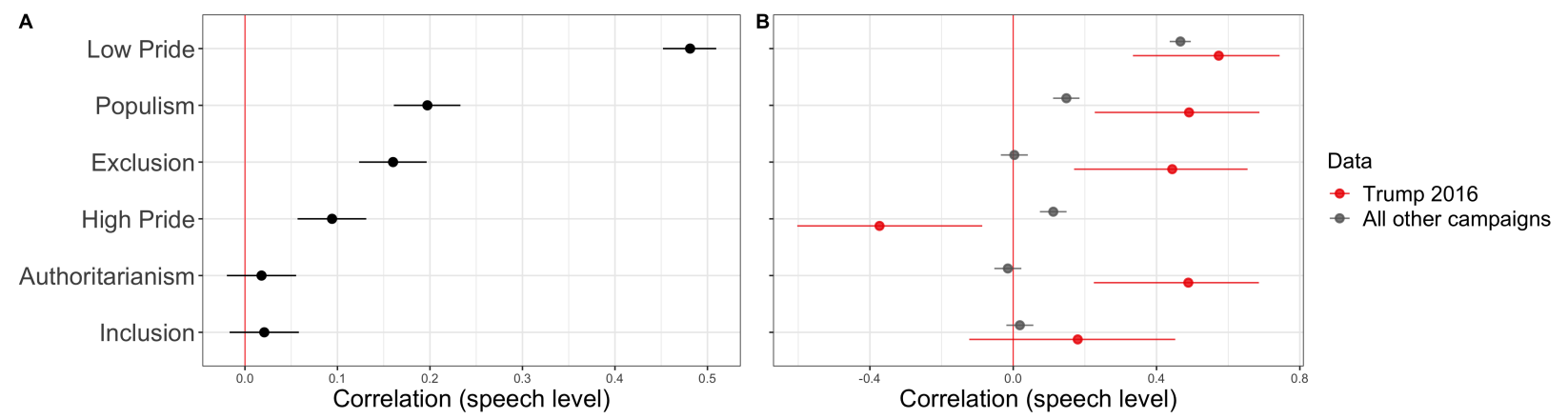

Note: Speech-level analysis; $\mathrm{N}=2,739$ (Panel A), $\mathrm{N}=2,707$ (Panel $\mathrm{B}$, other campaigns), and $\mathrm{N}=32$ (Panel B, Trump 2016); bars denote 90\% confidence intervals for Trump 2016 data (given small sample size) and $95 \%$ confidence intervals for the other analyses; because we lack predictions for the other frames for both 2020 campaigns, the associations shown are limited campaigns between 1952 and 2016; since the other frames were classified with a .5 probability threshold, we use the same threshold for classifying nostalgia in this analysis.

\section{Nostalgia, Populism, Nationalism, and Authoritarianism}

Our final analysis examines the relationship between nostalgia and other frames commonly found in radical-right discourse, most of which have had mainstream antecedents (Bonikowski et al., 2021). Specifically, we ask whether nostalgia is associated with populism, exclusionary nationalism, authoritarianism, and expressions of low national pride. We also examine two counter-frames - inclusive nationalism and high national pride - to test for possible asymmetries in the association of nostalgia with inclusion-exclusion and pride. All of the frames aside from nostalgia come from a previous study in which we used a RoBERTa classifier to annotate the same corpus (Authors 2021).

The results are presented in figure 6. The correlation coefficients in panel A, sorted in descending order by magnitude, show the degree to which each frame co-occurs with nostalgia within all campaign speeches. Not surprisingly, evocations of low national pride exhibit the highest correlation with nostalgia at 0.48. Low-pride frames depict the nation in a negative light and therefore overlap conceptually with nostalgic claims, though the latter also supplement the critique with a glorification of the past. We therefore view this result as an additional face validity check for the quality of our machine-based classification. Given that feelings of low national pride (combined with ethnonationalism) were predictive of Trump support in the 2016 election (Bonikowski et al., 2019), this finding may also have substantive implications, connecting nostalgia with the kind of radical-right rhetoric observed in the Trump campaign.

Another frame central to radical-right discourse - but also commonly found in mainstream U.S. politics - is populism (Mudde, 2007; Fahey, 2021). This moral vilification of elites and concomitant glorification of "the people" overlaps with low national pride to the degree that it depicts the present political moment in a critical light, but unlike low pride, 
it is more explicitly focused on attributing blame for the situation to the political establishment. As figure 6 shows, populism is also positively correlated with nostalgia $(\mathrm{r}=0.2)$. In addition to framing the present in negative terms, offering a positive view of a lost past may allow candidates - especially challengers - to portray themselves as the rightful representatives of the popular will, who alone can reclaim the national glory that has been forsaken by the corrupt elites.

The third element of radical-right politics on which we focus is exclusionary nationalist discourse. Unlike populism and evocations of low national pride, this frame was only infrequently used in an explicit manner prior to the 2016 Trump campaign (Bonikowski et al., 2021). We observe a positive correlation $(\mathrm{r}=0.16)$ between the use of nostalgia and exclusionary nationalism at the speech level across our time series, which suggests that at least in some of its instantiations, nostalgia may indeed serve as a dog whistle for racial resentment, with its depiction of a bygone national era signaling a time when the racial status hierarchy in the United States was more stable, with whites unquestionably at the top. As expected however, given the dearth of exclusionary language prior to 2016, the correlation is reduced to 0 once the Trump campaign is removed from the analysis (a point to which we return below).

The fourth frame typically associated with radical-right discourse is authoritarianismthat is, disregard for democratic norms, undermining of democratic institutions, and threats of excessive and unequal use of state power against citizens. We expected this frame to be associated with nostalgia, with declinist narratives and promises of the restoration of a glorified past providing a justification for authoritarian governance. This turned out not to be the case, as we observe no significant association between these two frames in our corpus. To the degree that presidential candidates sought to capitalize on citizens' concerns over crime and government corruption by promising punitive and strong-handed solutions, they appear to do so so without reference to reclaiming a more stable past.

Finally, our analysis includes two frames that are not intrinsic to radical-right discourse, but instead function as alternatives - or perhaps even counter-frames - to such discourse. The first is the expression of high pride in the nation, often interpreted as patriotism (Huddy and Khatib, 2007). The second is inclusive nationalism that emphasizes the importance of diversity and inclusion as core American values. We see no significant correlation between inclusive nationalism and nostalgia, perhaps not surprisingly so, given that historically the U.S. has been less rather than more inclusive of racial, ethnic, and religious minorities. Interestingly, however, patriotic claims do exhibit a low but significant correlation with nostalgia. This may seem counterintuitive given that a critical depiction of the nation's present state is constitutive of nostalgic claims, but one possible interpretation of this finding is that such critiques can be effectively combined with statements celebrating the nation's timeless values and persistent ability to overcome crises. This enables candidates to express a sense of optimism about the future and to preempt charges of underappreciated the nation's accomplishments and potential.

The frame correlation results thus far were based on the corpus as a whole. Throughout this paper, however, we have distinguished mainstream campaigns from radical ones, 
and sought to identify points of continuity and difference between them. Moreover, our initial discussion of radical-right discourse argued that nostalgia may fuse together populist, ethnonationalist, and authoritarian frames - a claim that is plausible but has not been empirically tested. For both reasons, it is important to examine the correlations between nostalgia and other frames separately for the 2016 Trump campaign and the rest of our data.

We do so in panel B of figure 6. The results are striking. Among Trump speeches, nostalgia is strongly positively associated with low pride, populism, exclusionary nationalism, and authoritarianism, and it is negatively associated with patriotism (i.e., high national pride). That is, the structure of Trump's discourse closely adheres to the dominant conceptualization of radical-right politics in the literature (Bonikowski, 2017; Mudde, 2007; Rooduijn, 2014) and nostalgia appears to play a central role in tying together the campaign's radical-right themes.

When the analysis is limited to mainstream campaigns, the associations of nostalgia with low pride, populism, and high pride observed in the corpus as a whole are largely unaffected, reinforcing our interpretation of the findings in panel A of figure 6 . The association between nostalgia and exclusionary nationalism, however, is reduced to zero (as we had noted earlier), because nearly all instances of exclusionary nationalism in the corpus are attributable to Donald Trump. And as before, there is no significant association between nostalgia and authoritarianism in mainstream campaign speeches.

The results of the correlation analysis confirm our conceptualization of nostalgia as a discursive device capable of linking together other frames commonly observed on the radical right, particularly populism, exclusionary nationalism, authoritarianism, and negative assessments of the national present (i.e., expressions of low national pride). Two of these associations in particular - with populism and low pride - were commonly observed in Republican and Democratic campaigns spanning over six decades, from 1952 to 2016. This suggests that the deployment of nostalgia by political challengers to critique the status quo and undermine their incumbent opponents had been a well established practice in mainstream U.S. politics well before Donald Trump's rise to prominence.

It is important to note, however, that mainstream political campaigns rarely engage in explicit exclusionary nationalism and to the degree that they make authoritarian claims, they appear not to do so through references to lost national glory. Moreover, as the content analysis of nostalgic paragraphs and the bipartisan reliance on nostalgic frames suggest, the use of nostalgia in mainstream political discourse is not limited to negative assessments of the present, whether in the service of populist claims or as expressions of low national pride - nostalgia can also be used to bolster arguments in favor of greater investments in infrastructure and education and increased redistribution, as well as to celebrate the nation's timeless values and express patriotic pride.

\section{Discussion}

Our study has revealed nostalgia to be a common feature of U.S. presidential politics since the 1950s. Its use spans the ideological spectrum and extends well beyond radical politics 
to mainstream candidates from both parties, particularly those competing against nominees of the incumbent party. Nostalgic rhetoric, as our results show, is typically succinct and multivocal; rather than painting a rich picture of a particular bygone era, most candidates simply assert that the nation is in decline and let the audience infer why this is the case and when things were ostensibly better (in contrast, the solution to the problem is always straightforward: by electing the candidate making the nostalgic appeals, the nation's lost glory can be restored). Even though the formal structure of nostalgia is relatively uniform across the corpus, the substantive topics framed in nostalgic terms differ by party: Democrats tend to use this strategy to advocate for government spending, whereas Republicans use it to challenge government power and, to a lesser degree, to pursue foreign policy objectives and signal the deterioration of national values. Finally, although nostalgia is found throughout the 69-year period covered by our corpus, its prevalence has varied over time: the 1950s and early 1960s, as well as the late 1990s through early 2000s, were marked by low levels of nostalgia, whereas the strategy was much more common in the late 1960s through the early 1990s and then again from 2008 onward. It is difficult to ascertain what explains this pattern, but we conjecture that one important factor may the degree to which political culture is in a relatively "settled" period versus one characterized by widespread contention over shifting racial status hierarchies, protracted wars, or crises of democratic representation.

These findings make several contributions to research on political communication, electoral campaigns, and radical-right politics. First, by examining political speeches spanning nearly the entirety of U.S. history since the Second World War, we are able to provide a rigorous, in-depth analysis of the form, content, and prevalence of nostalgic claims. The resulting substantive insights provide scholars of both mainstream and radical politics with a clearer picture of which candidates rely on this framing strategy, when they are most likely to do so, what issues they express in nostalgic terms, and how this strategy fits into their broader discursive repertoires. The finding that nostalgia tends to take on a simple and multivocal form is particularly interesting given the range of other options available to political campaigns. Candidates could easily rely on richer historical accounts to more concretely articulate what aspects of what specific past have been lost or abandoned. That they rarely do so presents a puzzle. We have conjectured that this is so because less definitive nostalgic claims may resonate with a more heterogeneous audience, which can infer a wide range of content into vague references about the past. Future research could test this mechanism directly with experimental methods.

Second, even though nostalgia is considered to be a prominent feature of radical-right politics, our study demonstrates that it is not exclusively so - on the contrary, this rhetorical strategy has long-established origins in mainstream U.S. politics. Both Democratic and Republican presidential nominees have routinely relied on it for decades to frame a wide range of issues, only some of which align with the arguments of the radical right. Despite differences in objectives, the mainstream use of nostalgia has legitimated this political trope and demonstrated its effectiveness, thereby making it a readily available strategic tool for radical actors. The resulting process of adoption mirrors the trajectory of other frames associated with the radical right, such as populism and expressions of low national pride, 
which have also moved over time from the mainstream to the extreme (Bonikowski et al., 2021). This suggests that radical-right discourse, for most part, does not represent a sharp break with politics as usual, but rather entails the repurposing of existing strategic tools for new ends - ends that undermine the integrity of the same mainstream politics from which the strategies originate.

Third, to the degree that discursive frames do travel from the mainstream to the extreme, our results suggest why nostalgia (as well as populism and low national pride, with which it is highly correlated) is particularly susceptible to this process. Since nostalgia, like the other two frames, depicts the present state of the nation in negative terms, it is an ideal strategy for political challengers. It allows them to indict the failures of the incumbents and the political establishment to which the incumbents belong, while portraying themselves as unsullied outsiders who, if elected, are uniquely able to restore the nation's greatness. It is this structural position that aligns mainstream candidates prone to using nostalgia with their radical-right counterparts, for what are radical-right actors if not outsider challengers par excellence. ${ }^{4}$

Fourth, just as our study shows the continuities between the mainstream and the radical right, it also reveals some important differences. Perhaps because they are not subject to the same common challenger-incumbent dynamics, neither nationalism nor authoritarianism are associated with nostalgia in mainstream campaigns, even though these frames are highly correlated in radical-right discourse. Therein lies the radical-right's innovation: the 2016 Trump campaign appears to have borrowed nostalgia, populism, and low national pride from mainstream candidates (among whom these three frames had long been correlated) and bundled them with explicit exclusionary nationalism (which had been virtually non-existent in prior presidential campaign discourse) and authoritarianism (which had been commonplace but not tied directly to nostalgic frames). The result is a discursive formula in which nostalgia functions as a mechanism fusing populist, nationalist, and authoritarian claims. By foregrounding a past when the nation belonged to the white majority and framing morally corrupt political elites and their minority allies as the agents of national decline, radical-right actors emerge as the champions of "the people" who are uniquely able to restore the nation's greatness - by any means necessary, including the undermining of liberal democratic norms and institutions.

Finally, in addition to the above substantive and theoretical contributions, by identifying the succinct lexical signature of nostalgia and showcasing cutting-edge machine learning tools for its automated detection in large textual corpora, our study opens the door to future research on this topic, both in the United States and in other democracies. Systematically measuring nostalgia in other political corpora can enable scholars to examine a wide range of questions. For instance, does nostalgia take on a similar or distinct form in countries with varied political cultures and institutional systems? Do nostalgic frames differ in their content and structure between local and federal elections or in legislative versus electoral politics?

\footnotetext{
${ }^{4}$ This raises the question of whether radical-left candidates would also be likely to employ this strategy. Their challenger status would suggest that they may, but the progressive rather than conservative ideology of the radical left could make declinist narratives less appealing for their purposes. Given the absence of radical-left politicians in our data, adjudicating these hypotheses is a task for future research.
} 
Does nostalgia's role as a fusing mechanism connect similar frames across all variants of radical-right politics? Do radical-left actors also employ nostalgic claims and if so, in what manner? Finally what kinds of nostalgic frames are most resonant for which audiences? We hope that the approach featured in this paper can serve as a starting point for such inquiry.

More broadly, we believe that research on party politics would benefit from closer attention to the continuities and differences between mainstream and radical discourse, as well as the discursive mechanisms that fuse together the core frames used by radical candidates. This paper takes steps in both directions. The recent surge of radical parties and candidates in democratic politics can give the impression that their approach to political mobilization is wholly novel - or to the degree that it has antecedents, those are to be found in historical cases of radicalism, such as early-twentieth-century fascism. Whatever the merits of such comparisons may be, radical actors are not inventing their politics de novo nor are they simply drawing on the repertoires of their distant historical precursors. They are also borrowing, adapting, and creatively recombining discursive strategies that have long been commonplace in mainstream politics. Furthermore, in so doing, they are adopting not only existing master frames - such as populism, nationalism, or authoritarianism-but also the rhetorical devices that link them, heightening their coherence and resonance. The result is a powerful mobilizing strategy that has enabled the radical right to gain newfound prominence in contemporary democracies. 


\section{References}

Abascal, Maria. 2020. "Contraction as a Response to Group Threat: Demographic Decline and Whites' Classification of People Who Are Ambiguously White." American Sociological Review 85:298-322.

Annenberg. 2000. The Annenberg/Pew Archive of Presidential Campaign Discourse. Philadelphia, PA: The Annenberg School for Communication.

Bai, Hui and Christopher M Federico. 2021. "White and Minority Demographic Shifts, Intergroup Threat, and Right-Wing Extremism." Journal of Experimental Social Psychology 94:104114.

Bates, Toby Glenn. 2011. The Reagan Rhetoric: History and Memory in 1980s America. DeKalb, IL: Northern Illinois University Press.

Betz, Hans-Georg and Carol Johnson. 2004. "Against the Current-Stemming the Tide: The Nostalgic Ideology of the Contemporary Radical Populist Right." Journal of Political Ideologies 9:311-327.

Bobo, Lawrence, James R Kluegel, and Ryan A Smith. 1997. "Laissez-Faire Racism: The Crystallization of a Kinder, gentler, Antiblack Ideology." In Racial Attitudes in the 1990s: Continuity and Change, edited by S.A. Tuch and J.K. Martin, volume 15, pp. 23-25. Westport, CT: Praeger.

Bobo, Lawrence D. 1999. "Prejudice as Group Position: Microfoundations of a Sociological Approach to Racism and Race Relations." Journal of Social Issues 55:445-472.

Bonikowski, Bart. 2017. "Ethno-Nationalist Populism and the Mobilization of Collective Resentment." The British Journal of Sociology 68:S181-S213.

Bonikowski, Bart, Yuval Feinstein, and Sean Bock. 2019. "The Partisan Sorting of 'America': How Nationalist Cleavages Shaped the 2016 U.S. Presidential Election." SocArXiv https://osf.io/preprints/socarxiv/pmg95/.

Bonikowski, Bart and Noam Gidron. 2016. "The Populist Style in American Politics: Presidential Campaign Discourse, 1952-1996." Social Forces 94:1593-1621.

Bonikowski, Bart, Yuchen Luo, and Oscar Stuhler. 2021. "Politics as Usual? Antecedents of Radical-Right Frames in U.S. Electoral Discourse." SocArXiv .

Bonikowski, Bart and Yueran Zhang. 2019. "Populism as Dog-Whistle Politics: Anti-Elite Discourse and Sentiments toward Minorities." SocArXiv .

Bonikowski, Bart and Daniel Ziblatt. 2020. "Mainstream Conservative Parties Paved the Way for Far-Right Nationalism." The Washington Post, Monkey Cage Dec. 2. 
Bonilla-Silva, Eduardo. 2006. Racism Without Racists: Color-Blind Racism and the Persistence of Racial Inequality in the United States. New York: Rowman \& Littlefield Publishers.

Crabtree, Charles, Matt Golder, Thomas Gschwend, and Indriđi H Indriđason. 2020. "It Is Not Only What You Say, It Is Also How You Say It: The Strategic Use of Campaign Sentiment." The Journal of Politics 82:1044-1060.

Craig, Maureen A. and Jennifer A. Richeson. 2014. "More Diverse Yet Less Tolerant? How the Increasingly Diverse Racial Landscape Affects White Americans' Racial Attitudes." Personality and Social Psychology Bulletin 40:750-761. PMID: 24625658.

Dai, Yaoyao and Alexander Kustov. 2020. "When Do Politicians Use Populist Rhetoric? Populism as a Campaign Gamble." Unpublished manuscript.

Dai, Yaoyao and Alexander Kustov. 2021. "When Do Politicians Use Populist Rhetoric: Populism as a Campaign Gamble." Unpublished Manuscript. .

Danbold, Felix and Yuen J Huo. 2015. "No Longer "All-American"? Whites' Defensive Reactions to Their Numerical Decline." Social Psychological and Personality Science 6:210-218.

Dor, Liat Ein, Alon Halfon, Ariel Gera, Eyal Shnarch, Lena Dankin, Leshem Choshen, Marina Danilevsky, Ranit Aharonov, Yoav Katz, and Noam Slonim. 2020. "Active Learning for BERT: An Empirical Study." In Proceedings of the 2020 Conference on Empirical Methods in Natural Language Processing (EMNLP), pp. 7949-7962.

Duyvendak, Jan. 2011. The Politics of Home: Belonging and Nostalgia in Europe and the United States. New York: Palgrave Macmillan.

Elgenius, Gabriella and Jens Rydgren. 2019. "Frames of Nostalgia and Belonging: The Resurgence of Ethno-Nationalism in Sweden." European Societies 21:583-602.

Fahey, James J. 2021. "Building Populist Discourse: An Analysis of Populist Communication in American Presidential Elections, 1896-2016." Social Science Quarterly 102:1268-1288.

Feinstein, Yuval. 2016. "Rallying Around the President: When and Why Do Americans Close Ranks Behind Their Presidents During International Crisis and War?" Social Science History 40:305-338.

Gest, Justin, Tyler Reny, and Jeremy Mayer. 2018. "Roots of the Radical Right: Nostalgic Deprivation in the United States and Britain." Comparative Political Studies 51:16941719.

Gorski, Philip S. and Samuel L Perry. 2022. The Flag and the Cross: White Christian Nationlism and the Threat to American Democracy. New York: Oxford University Press. 
Hawkins, Kirk A, Ryan E Carlin, Levente Littvay, and Cristóbal Rovira Kaltwasser. 2018. The Ideational Approach to Populism: Concept, Theory, and Analysis. Philadelphia, PA: Routledge.

Huddy, Leonie and Nadia Khatib. 2007. "American Patriotism, National Identity, and Political Involvement." American journal of political science 51:63-77.

Hughey, Matthew W. 2014. "White Backlash in the 'Post-Racial' United States." Ethnic and Racial Studies 37:721-730.

Jensen, Jeffrey L, Daniel Karell, Cole Tanigawa-Lau, Nizar Habash, Mai Oudah, and Dhia Fairus Shofia Fani. 2021. "Language Models in Sociological Research: An Application to Classifying Large Administrative Data and Measuring Religiosity." Sociological Methodology p. 00811750211053370.

Karakaya, Yağmur. 2020. "The Conquest of Hearts: The Central Role of Ottoman Nostalgia Within Contemporary Turkish Populism." American Journal of Cultural Sociology 8:125157.

Kenny, Michael. 2017. "Back to the Populist Future?: Understanding Nostalgia in Contemporary Ideological Discourse." Journal of Political Ideologies 22:256-273.

Liu, Yinhan, Myle Ott, Naman Goyal, Jingfei Du, Mandar Joshi, Danqi Chen, Omer Levy, Mike Lewis, Luke Zettlemoyer, and Veselin Stoyanov. 2019. "RoBERTa: A Robustly Optimized BERT Pretraining Approach." arXiv preprint arXiv:190\%.11692 .

López, Ian Haney. 2015. Dog whistle politics: How coded racial appeals have reinvented racism and wrecked the middle class. New York: Oxford University Press.

Major, Brenda, Alison Blodorn, and Gregory Major Blascovich. 2018. "The Threat of Increasing Diversity: Why Many White Americans Support Trump in the 2016 Presidential Election." Group Processes 83 Intergroup Relations 21:931-940.

Maxwell, Angie and Todd Shields. 2019. The Long Southern strategy: How chasing White Voters in the South Changed American Politics. New York: Oxford University Press.

Mudde, Cas. 2007. Populist Radical Right Parties in Europe. Cambridge, UK: Cambridge University Press.

Muro, Diego. 2005. "Nationalism and Nostalgia: The Case of Radical Basque Nationalism." Nations and Nationalism 11:571-589.

Outten, H Robert, Michael T Schmitt, Daniel A Miller, and Amber L Garcia. 2012. "Feeling Threatened About the Future: Whites' Emotional Reactions to Anticipated Ethnic Demographic Changes." Personality and Social Psychology Bulletin 38:14-25. 
Richards, Lindsay, Anthony Heath, and Gabriella Elgenius. 2020. "Remainers Are Nostalgic Too: An Exploration of Attitudes Towards the Past and Brexit Preferences." The British Journal of Sociology 71:74-80.

Rooduijn, Matthijs. 2014. "The Nucleus of Populism: In Search of the Lowest Common Denominator." Government and Opposition 49:573-599.

Rydgren, Jens. 2005. "Is Extreme Right-Wing Populism contagious? Explaining the Emergence of a New Party Family." European journal of political research 44:413-437.

Saito, Takaya and Marc Rehmsmeier. 2015. "The Precision-Recall Plot Is More Informative Than the ROC Plot When Evaluating Binary Classifiers on Imbalanced Datasets." PloS one 10:e0118432.

Sedikides, Constantine, Tim Wildschut, Jamie Arndt, and Clay Routledge. 2008. "Nostalgia: Past, Present, and Future." Current directions in psychological science 17:304-307.

Sedikides, Constantine, Tim Wildschut, Clay Routledge, and Jamie Arndt. 2015. "Nostalgia Counteracts Self-Discontinuity and Restores Self-Continuity." European Journal of Social Psychology 45:52-61.

Smeekes, Anouk, Maykel Verkuyten, and Borja Martinovic. 2015. "Longing for the Country's Good Old Days: National Nostalgia, Autochthony Beliefs, and Opposition to Muslim Expressive Rights." British Journal of Social Psychology 54:561-580.

Smith, Anthony D. 2009. Ethno-Symbolism and Nationalism: A Cultural Approach. London, UK: Routledge.

Steenvoorden, Eefje and Eelco Harteveld. 2018. "The Appeal of Nostalgia: The Influence of Societal Pessimism on Support for Populist Radical Right Parties." West European Politics 41:28-52.

Stewart, Sheridan and Robb Willer. 2021. "The Effects of Racial Status Threat on White Americans' Support for Donald Trump: Results of Five Experimental Tests." Group Processes 6 Intergroup Relations p. 13684302211048893.

Szabó, Gabriella and Balázs Kiss. 2021. "Sharing Political Nostalgia in Hungary: Is Yearning for the Past Successful on Social Media?" Innovation: The European Journal of Social Science Research pp. 1-22.

Terechshenko, Zhanna, Fridolin Linder, Vishakh Padmakumar, Michael Liu, Jonathan Nagler, Joshua A Tucker, and Richard Bonneau. 2020. "A Comparison of Methods in Political Science Text Classification: Transfer Learning Language Models for Politics." SSRN .

UCSB. 2021. The American Presidency Project. Santa Barbara, CA: UC Santa Barbara. 
Vaswani, Ashish, Noam Shazeer, Niki Parmar, Jakob Uszkoreit, Llion Jones, Aidan N Gomez, Lukasz Kaiser, and Illia Polosukhin. 2017. "Attention Is All You Need." arXiv 1706.03762.

Wetts, Rachel and Robb Willer. 2019. "Who is Called by the Dog Whistle? Experimental Evidence That Racial Resentment and Political Ideology Condition Responses to racially Encoded Messages." Socius 5:2378023119866268.

Whitehead, Andrew L and Samuel L Perry. 2020. Taking America Back for God: Christian Nationalism in the United States. Oxford University Press.

Willer, Robb, Matthew Feinberg, and Rachel Wetts. 2016. "Threats to Racial Status Promote Tea Party Support Among White Americans." SSRN 2770186.

Wohl, Michael JA and Anna Stefaniak. 2020. "Collective Nostalgia and the Desire to Make One's Group Great Again." In Applications of Social Psychology, edited by Joseph P. Forgas, William D. Crano, and Klaus Fiedler, pp. 292-311. London, UK: Routledge. 


\section{Appendices}

\section{A Corpus descriptive statistics}

Table A.1: Campaign level summary statistics

\begin{tabular}{lcccccc}
\hline Variable & $\mathrm{N}$ & Mean & Min & Max & Sd & Median \\
\hline $\begin{array}{l}\text { Mean share of nostalgic } \\
\text { paragraphs }\end{array}$ & 35 & 0.029 & 0.001 & 0.095 & 0.023 & 0.020 \\
Republican $(1=$ yes $)$ & 35 & 0.486 & 0 & 1 & 0.507 & 0 \\
Prior president $(1=$ yes $)$ & 35 & 0.314 & 0 & 1 & 0.471 & 0 \\
Incumbent party $(1=$ yes $)$ & 35 & 0.514 & 0 & 1 & 0.507 & 1 \\
\hline
\end{tabular}

Table A.2: Proportion of discursive frames within speeches

\begin{tabular}{lcccccc}
\hline Variable & $\mathrm{N}$ & Mean & Min & Max & Sd & Median \\
\hline Nostalgia & 2,795 & 0.044 & 0 & 0.714 & 0.072 & 0 \\
Populism & 2,739 & 0.032 & 0 & 1 & 0.074 & 0 \\
Authoritarianism & 2,739 & 0.009 & 0 & 0.621 & 0.042 & 0 \\
Inclusive nationalism & 2,739 & 0.056 & 0 & 1 & 0.112 & 0 \\
Exclusive nationalism & 2,739 & 0.003 & 0 & 0.361 & 0.021 & 0 \\
Low pride & 2,739 & 0.054 & 0 & 0.800 & 0.087 & 0 \\
High pride & 2,739 & 0.086 & 0 & 0.667 & 0.101 & 0.060 \\
\hline
\end{tabular}

Note: For the correlation analysis, we identify nostalgic paragraphs using a probability threshold of .5-rather than a threshold premised on achieving a precision of .8 , as in previous analyses - in order to match the measurement approach used by [Authors 2021] for classifying the other six frames. 
Table A.3: Speeches per campaign

\begin{tabular}{|c|c|c|}
\hline Campaign & $\mathrm{N}$ & $\begin{array}{c}\text { Share of } \\
\text { nostalgic } \\
\text { paragraphs }\end{array}$ \\
\hline 1952 Eisenhower & 218 & 0.005 \\
\hline 1952 Stevenson & 170 & 0.003 \\
\hline 1956 Eisenhower & 36 & 0.007 \\
\hline 1956 Stevenson & 72 & 0.020 \\
\hline 1960 Kennedy & 259 & 0.035 \\
\hline 1960 Nixon & 136 & 0.002 \\
\hline 1964 Johnson & 109 & 0.005 \\
\hline 1968 Humphrey & 144 & 0.007 \\
\hline 1968 Nixon & 54 & 0.051 \\
\hline 1972 McGovern & 87 & 0.055 \\
\hline 1972 Nixon & 52 & 0.008 \\
\hline 1976 Carter & 50 & 0.070 \\
\hline 1976 Ford & 114 & 0.017 \\
\hline 1980 Carter & 88 & 0.017 \\
\hline 1980 Reagan & 65 & 0.060 \\
\hline 1984 Mondale & 65 & 0.036 \\
\hline 1984 Reagan & 108 & 0.034 \\
\hline 1988 Bush & 41 & 0.019 \\
\hline 1988 Dukakis & 64 & 0.042 \\
\hline 1992 Bush & 122 & 0.022 \\
\hline 1992 Clinton & 76 & 0.045 \\
\hline 1996 Clinton & 110 & 0.005 \\
\hline 1996 Dole & 75 & 0.018 \\
\hline 2000 Gore & 4 & 0.016 \\
\hline 2004 Bush & 109 & 0.001 \\
\hline 2004 Kerry & 28 & 0.046 \\
\hline 2008 McCain & 33 & 0.051 \\
\hline 2008 Obama & 51 & 0.048 \\
\hline 2012 Obama & 82 & 0.019 \\
\hline 2012 Romney & 47 & 0.060 \\
\hline 2016 Clinton & 37 & 0.009 \\
\hline 2016 Trump & 32 & 0.095 \\
\hline 2020 Biden & 43 & 0.022 \\
\hline 2020 Trump & 13 & 0.016 \\
\hline
\end{tabular}




\section{B Content analysis of nostalgic paragraphs}

Table B.1: Coding of themes in nostalgic paragraphs

\begin{tabular}{|c|c|c|}
\hline Theme & Keywords & Example \\
\hline $\begin{array}{l}\text { Infrastructure and } \\
\text { education }\end{array}$ & $\begin{array}{l}\text { bridges, colleges, crumbling, educa- } \\
\text { tion, electricity, grid, infrastructure, } \\
\text { roads, schools, teachers, universities }\end{array}$ & $\begin{array}{l}\text { "[...] I'll invest in rebuilding our } \\
\text { crumbling infrastructure - our roads, } \\
\text { schools, and bridges. We'll rebuild } \\
\text { our outdated electricity grid [...]." } \\
\text { - Obama } 08\end{array}$ \\
\hline $\begin{array}{l}\text { Economy and wel- } \\
\text { fare state }\end{array}$ & $\begin{array}{l}\text { business, coal, economic, economy, } \\
\text { factories, factory, fair share, food } \\
\text { stamps, growth, hard work, hard- } \\
\text { ship, income, industrial, industry, } \\
\text { inflation, jobs, labor, manufactur- } \\
\text { ing, middle class, middle-class, op- } \\
\text { portunity, pay the bills, paycheck, } \\
\text { poverty, productivity, prosperity, re- } \\
\text { cession, small business, social secu- } \\
\text { rity, steel, the poor, trade, trickle- } \\
\text { down, unemployed, unemployment, } \\
\text { worker, working class, working-class }\end{array}$ & $\begin{array}{l}\text { "I am going to bring back your jobs. } \\
{[\ldots] \text { We will make Michigan the eco- }} \\
\text { nomic envy of the world once again." } \\
\text { - Trump } 16\end{array}$ \\
\hline National values & $\begin{array}{l}\text { character, compassion, decency, } \\
\text { democracy, fairness, faith, fellow } \\
\text { human being, freedom, honesty, hu- } \\
\text { man rights, idealism, ideals, justice, } \\
\text { liberties, liberty, moral, patriot, } \\
\text { principles, spirit, traditional, values, } \\
\text { wisdom }\end{array}$ & $\begin{array}{l}\text { "I am also determined to see another } \\
\text { kind of faith restored and strength- } \\
\text { ened in America. I speak of the } \\
\text { religious faith, the moral and spiri- } \\
\text { tual values that have been so basi- } \\
\text { cally a part of our American experi- } \\
\text { ence. [...] [T]he strength of our char- } \\
\text { acter, the strength of our faith, and } \\
\text { the strength of our ideals-these have } \\
\text { been the strength of America." } \\
\text { - Nixon } 72\end{array}$ \\
\hline Law and order & $\begin{array}{l}\text { afraid to walk, crime, criminal, } \\
\text { dealer, drug, enforce, gang, officer, } \\
\text { police, riot, safe, secure, violence, vi- } \\
\text { olent, without being afraid }\end{array}$ & $\begin{array}{l}\text { "I know that America can indeed [...] } \\
\text { turn back the threat of drugs and } \\
\text { crime, the fear of our young and old, } \\
\text { and make our communities safe and } \\
\text { strong and secure once again." } \\
\text { - Bush } 92\end{array}$ \\
\hline
\end{tabular}




$\begin{array}{ll}\text { Foreign policy } & \text { abroad, Africa, allies, ally, Asia, "I pledge to you the new foreign pol- } \\ & \text { Communism, defense, dictators, ene- icy that will restore respect for Amer- } \\ & \text { mies, enemy, Europe, foreign, global, ica around this world [...]." } \\ & \text { international, Latin America, Mid- - Nixon } 68 \\ & \text { East, Middle East, military, national } \\ & \text { security, nations, NATO, nuclear, } \\ & \text { peace, respect for America, troops, } \\ & \text { war, weapons, world } \\ & \text { back our government, big govern- "It is time for a president who will } \\ & \text { ment, bureaucracies, bureaucracy, bring the government back to the } \\ & \text { bureaucrat, competence, competent, people." } \\ \text { Government } & \text { congress back, corrupt, drain the - McGovern } 72 \\ & \text { swamp, elite, establishment, govern- } \\ & \text { ment back, government that works, } \\ & \text { government work, infighting, in- } \\ & \text { tegrity, lobbyists, ordinary people, } \\ & \text { politicians, returning power, scandal, } \\ & \text { secret, selfishness, special interest }\end{array}$


Table B.2: Descriptive statistics for substantive themes identified in nostalgic paragraphs

\begin{tabular}{lccccccc}
\hline Statistic & N & Mean & St. Dev. & Min & Pctl(25) & Pctl(75) & Max \\
\hline National values & 33 & 0.721 & 0.470 & 0.122 & 0.346 & 0.999 & 2.041 \\
Government integrity & 33 & 0.193 & 0.260 & 0.000 & 0.023 & 0.229 & 1.204 \\
Foreign policy & 33 & 1.172 & 0.591 & 0.384 & 0.679 & 1.439 & 2.565 \\
Law and order & 33 & 0.241 & 0.319 & 0.000 & 0.030 & 0.320 & 1.537 \\
Economy and welfare state & 33 & 1.379 & 0.978 & 0.186 & 0.607 & 1.709 & 4.519 \\
Infrastructure and education & 33 & 0.163 & 0.239 & 0.000 & 0.000 & 0.203 & 1.164 \\
\hline
\end{tabular}

Note: Theme prevalence is measured as the share (in percent) of keywords among all words contained in a given campaign's nostalgic paragraphs. Al Gore's 2000 campaign was omitted because its coverage in our data is limited to four speeches with three nostalgic paragraphs. 


\section{Supplementary analyses}

Figure C.1: Nostalgia's association with populism, nationalism, and authoritarianism by party, mainstream campaigns only (i.e., Trump 2016 removed)

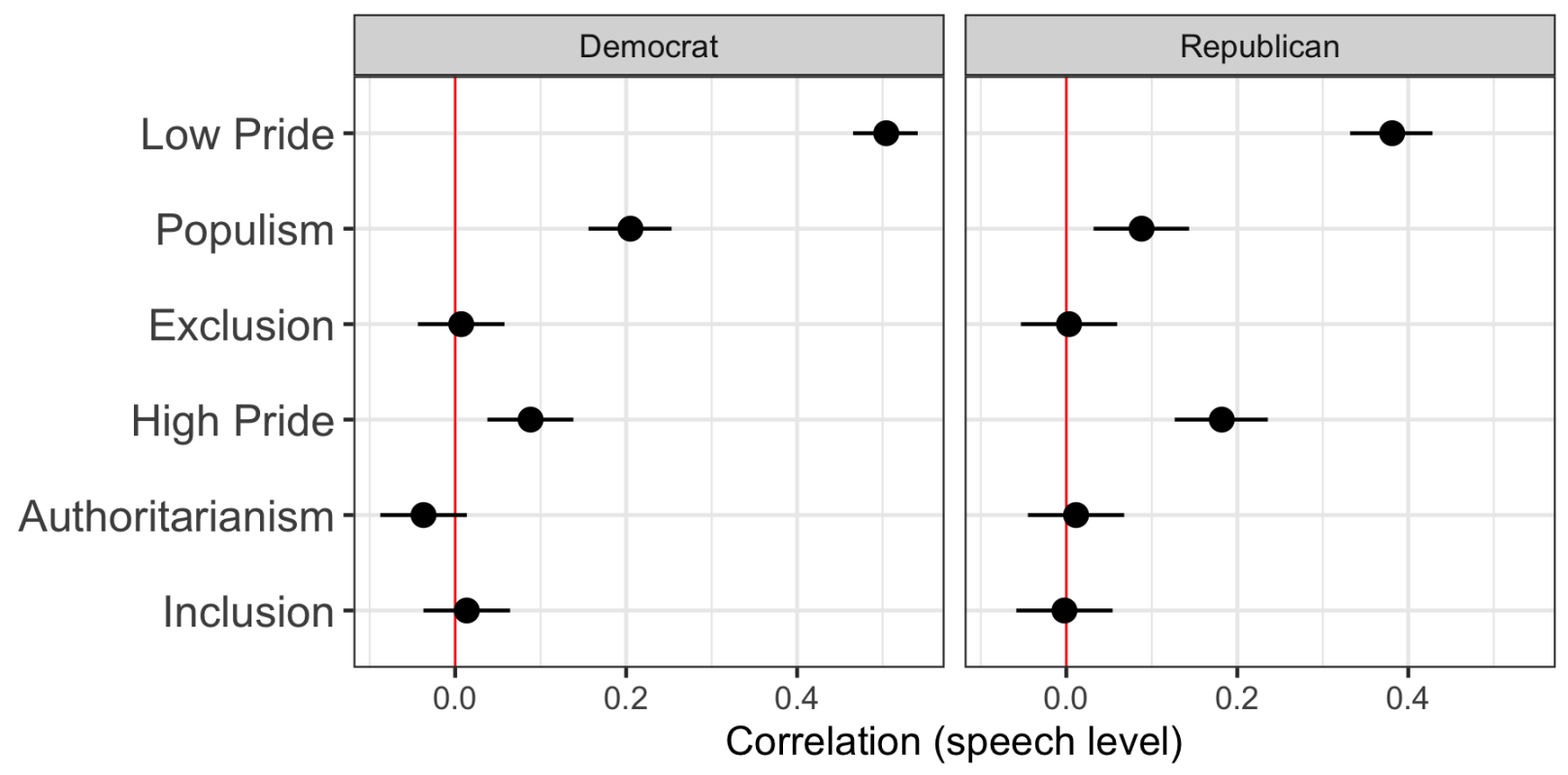

Note: Speech level analysis; $\mathrm{N}=1,224$ for Republicans and $\mathrm{N}=1,539$ for Democrats; bars denote $90 \%$ confidence intervals; because we lack predictions for the other frames for both 2020 campaigns, the analysis is limited to campaigns between 1952-2016; since the other frames were classified with a .5 probability threshold, we use the same threshold for classifying nostalgia in this analysis. 
Figure C.2: Campaign-level predictors of nostalgia (.5 cutoff)

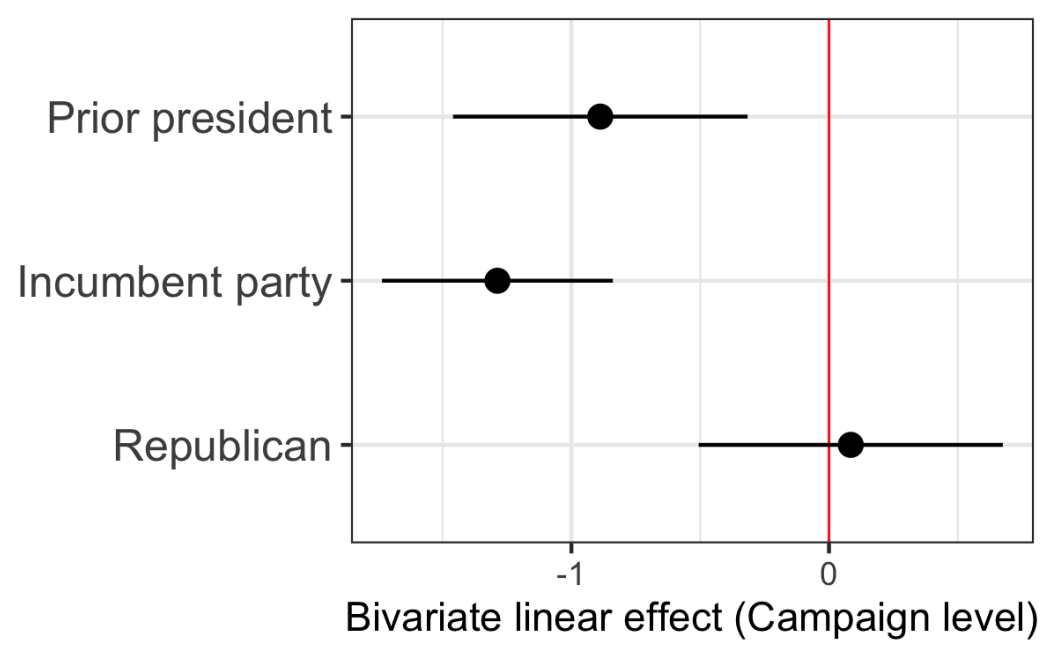

Figure C.3: Use of nostalgia by Democratic and Republican candidates, 1952-2020 (.5 cutoff)

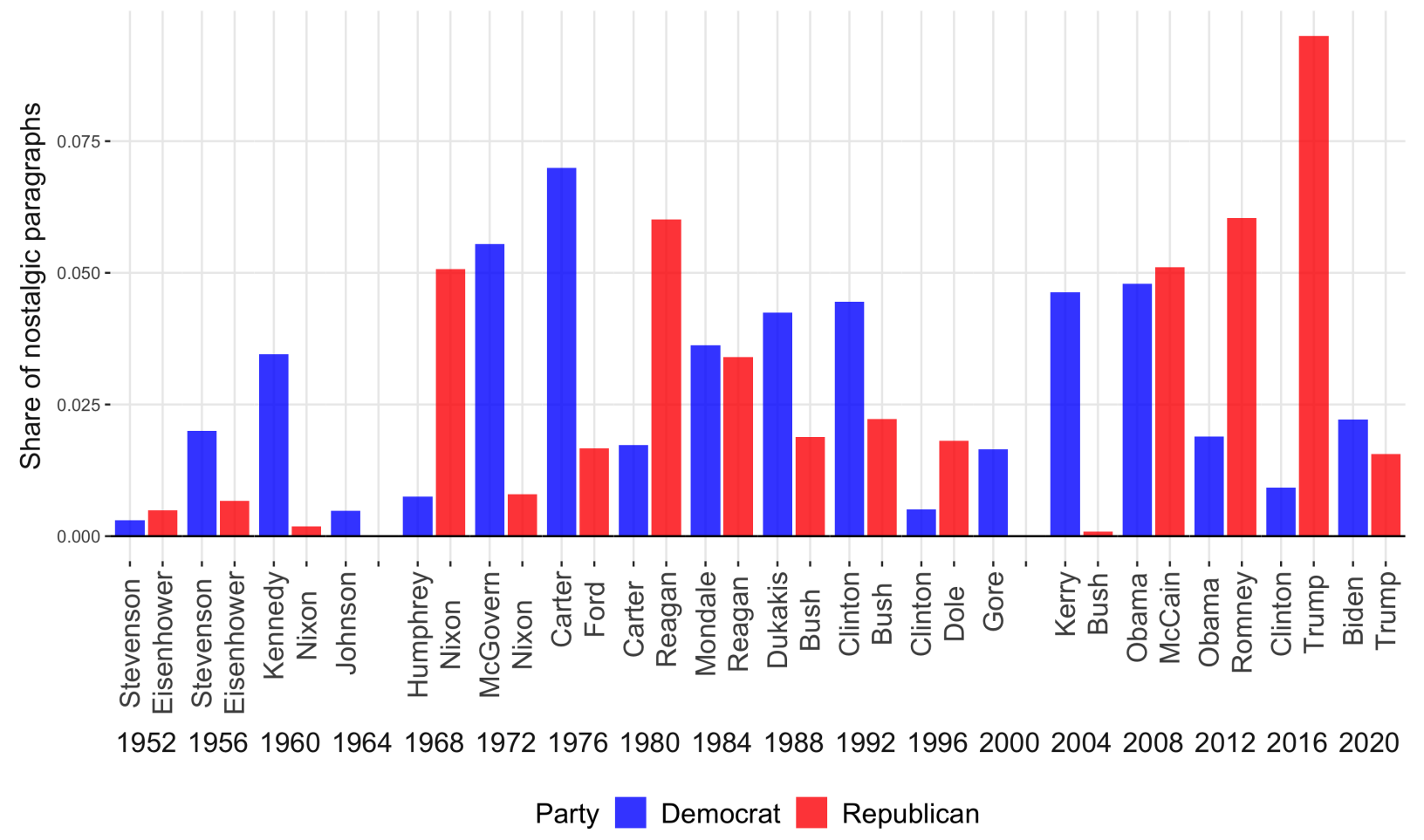

